\title{
High thermoelectric performance of all-oxide heterostructures with carrier double-barrier filtering effect
}

\begin{abstract}
Chunlin $\mathrm{Ou}^{1,4}$, Jungang $\mathrm{Hou}^{1,2,4}$, Tian-Ran $\mathrm{Wei}^{3}$, Bo Jiang ${ }^{1}$, Shuqiang Jiao ${ }^{1}$, Jing-Feng $\mathrm{Li}^{3}$ and Hongmin $\mathrm{Zhu}^{1,2}$
Thermoelectric materials can realize significant energy savings by generating electricity from untapped waste heat; however, the coupling of the thermoelectric parameters unfortunately limits their efficiency and practical applications. Herein, rational all-oxide $\mathrm{TiC}_{1-\mathrm{x}} \mathrm{O}_{\mathrm{x}} @ \mathrm{TiO}_{\mathrm{y}}-\mathrm{TiO}_{2}(\mathrm{x}<1,1<\mathrm{y}<2)$ heterostructures with significantly enhanced thermoelectric properties have been designed, and a high dimensionless figure of merit $(Z T)$ value of up to 0.84 at $973 \mathrm{~K}$ was achieved in the all-oxide $\mathrm{TiC}_{0.1} \mathrm{O}_{0.9} @ \mathrm{TiO}_{\mathrm{y}}-\mathrm{TiO}_{2}$ heterostructures, which is one of the highest values in $\mathrm{n}$-type oxide bulk thermoelectric materials to date. The $\mathrm{TiC}_{1-\mathrm{x}} \mathrm{O}_{\mathrm{x}} @ \mathrm{TiO}_{\mathrm{y}}$ heterostructures, which include a thin film of approximately $5-10 \mathrm{~nm}$ on the surface of $\mathrm{TiC}_{1-\mathrm{x}} \mathrm{O}_{\mathrm{x}}$ compounds prepared by a facile anodization process, exhibit an obvious improvement of the thermoelectric power factor. Furthermore, an excellent dimensionless figure of merit value was obtained in the $\mathrm{TiC}_{1-\mathrm{x}} \mathrm{O}_{\mathrm{x}} @ \mathrm{TiO}_{\mathrm{y}}-\mathrm{TiO}_{2}$ heterostructures prepared by the anodization process assisted by the sol-gel chemical route, which can be attributed to the decrease in the carrier concentration via the carrier double-barrier filtering effect. This work develops a facile strategy for synthesizing core-shell heterostructures and demonstrates their superior ability to optimize thermoelectric energy harvesting.
\end{abstract}

NPG Asia Materials (2015) 7, e182; doi:10.1038/am.2015.36; published online 22 May 2015

\section{INTRODUCTION}

Renewable energy initiatives have increased interest in thermoelectric materials as an option for inexpensive and environmentally friendly heat-to-electricity generation. ${ }^{1-5}$ The potential of a thermoelectric material is mainly determined by the dimensionless figure of merit: $Z T=\frac{\alpha^{2} \sigma}{\kappa} T$, where $\alpha, \sigma, \kappa$ and $\mathrm{T}$ are the Seebeck coefficient, electrical conductivity, thermal conductivity, and absolute temperature, respectively. ${ }^{6}$ It is apparent that a high-ZT material must possess a high Seebeck coefficient and electrical conductivity but low thermal conductivity; however, these parameters, which are determined by the electron and phonon systems, are closely interrelated. Therefore, the appropriate Seebeck coefficient, electrical conductivity and thermal conductivity should be expected. ${ }^{7,8}$ To date, commercial thermoelectric materials are mainly alloys and compounds. ${ }^{9-20}$ However, metal oxide semiconductors ${ }^{21-24}$ have attracted significant interest for thermoelectric power generation. Thus, it is a challenge to select the appropriate oxide thermoelectric (TE) system with high electrical conductivity.

Recently, titanium oxides have attracted particular interest as efficient TE materials with high electrical conductivity. ${ }^{25-29}$ Non-stoichiometry and doping can lead to a high- $Z T$ value because of the enhancement of the Seebeck coefficient and electrical conductivity. However, non-stoichiometric $\mathrm{TiO}_{\mathrm{x}}(1<\mathrm{x}<2)$ materials exhibit low thermal conductivity at high temperature. ${ }^{26}$ To overcome this drawback, $\mathrm{TiC}_{1-\mathrm{x}} \mathrm{O}_{\mathrm{x}}$ solid solutions with high electrical conductivity and good thermal stability were applied as TE materials. ${ }^{30-32}$ Therefore, $\mathrm{TiC}_{1-\mathrm{x}} \mathrm{O}_{\mathrm{x}}$ solid solutions are promising candidates as $\mathrm{TE}$ materials in the heat-to-electricity conversion field.

The strategy of rationally engineering semiconductor interfaces could enhance the $Z T$ in TE materials with the heterostructures, where the significant enhancement performance is believed to result from the growth of the Seebeck coefficient by the preferential scattering of low-energy carriers more effectively than high ones and the reduction of the thermal conduction via scattering phonons at the heterostructured interfaces. ${ }^{33-40}$ For example, SiC nano-inclusions possessing coherent interfaces with the $\mathrm{Bi}_{0.3} \mathrm{Sb}_{1.7} \mathrm{Te}_{3}$ matrix can increase the Seebeck coefficient. ${ }^{39} \mathrm{Te} / \mathrm{Bi}$ and $\mathrm{Te} / \mathrm{Bi}_{2} \mathrm{Te}_{3}$ core/shell heterostructures nanowires could greatly enhance the Seebeck coefficient and greatly reduce the thermal conductivity. ${ }^{40}$ Inspired by these precursory results, it is necessary to design rational heterostructures based on $\mathrm{TiC}_{1-\mathrm{x}} \mathrm{O}_{\mathrm{x}}$ solid solutions to achieve enhanced thermoelectric performance.

Here, we focused on rationally engineering all-oxide $\mathrm{TiC}_{1-\mathrm{x}} \mathrm{O}_{\mathrm{x}} @$ $\mathrm{TiO}_{\mathrm{y}}-\mathrm{TiO}_{2}$ heterostructures to improve the Seebeck coefficient via the carrier double-barrier filtering effect; furthermore, several important rules for constructing the heterostructures were considered.

\footnotetext{
${ }^{1}$ School of Metallurgical and Ecological Engineering, University of Science and Technology Beijing, Beijing, China; ${ }^{2}$ Tohoku University, Aoba-ku, Sendai, Japan and ${ }^{3}$ State Key Laboratory of New Ceramics and Fine Processing, School of Materials Science and Engineering, Tsinghua University, Beijing, China

${ }^{4}$ These authors contributed equally to this work.

Correspondence: Professor Dr H Zhu, Tohoku University, 6-6-02 Aramaki-Aza-Aoba, Aoba-ku, Sendai 980-8579, Japan.

E-mail: hzhu@ustb.edu.cn
}

Received 5 March 2014; revised 27 January 2015; accepted 2 March 2015 
The potential barrier of the all-oxide $\mathrm{TiC}_{1-\mathrm{x}} \mathrm{O}_{\mathrm{x}} @ \mathrm{TiO}_{\mathrm{y}}-\mathrm{TiO}_{2}$ heterostructured interface can be engineered by adjusting the anodization voltage, coating the content of $\mathrm{TiO}_{2}$ and the solid solution level of $\mathrm{TiC}_{1-\mathrm{x}} \mathrm{O}_{\mathrm{x}}$, leading to optimized carrier scattering at the heterostructured interface and thus enhancement of the TE performance. Using the heterostructure materials, we successfully demonstrated that thermoelectric performance can be greatly enhanced via heterostructure engineering.

\section{EXPERIMENTAL PROCEDURE}

High-purity powders of $\mathrm{TiC}, \mathrm{TiO}$ and tetra-butyl titanate (99.8\%, Aladdin) were used as raw materials to prepare the powders. $\mathrm{TiC}_{1-\mathrm{x}} \mathrm{O}_{\mathrm{x}}(\mathrm{x}<1)$ powders were synthesized by the solid-state reaction of stoichiometric amounts of $\mathrm{TiC}$ and $\mathrm{TiO}\left(99.99 \%\right.$, Aladdin). ${ }^{30}$ As-synthesized $\mathrm{TiC}_{1-\mathrm{x}} \mathrm{O}_{\mathrm{x}}$ powders $(5 \mathrm{~g})$ with $1 \mathrm{ml}$ of deionized water were pressed into 20 - $\mathrm{mm}$-diameter bulks under a pressure of $5 \mathrm{MPa}$ and then annealed for $3 \mathrm{~h}$ at $1073 \mathrm{~K}$ in a tubular resistance furnace under argon atmosphere to obtain porous pellets. The core-shell $\mathrm{TiC}_{1-\mathrm{x}} \mathrm{O}_{\mathrm{x}} @ \mathrm{TiO}_{\mathrm{y}}(\mathrm{x}<1,1<\mathrm{y}<2)$ heterostructure materials were prepared using a facile anodization process, where the as-annealed porous pellets were used as the anode, a silver disk was used as the cathode and $0.01 \mathrm{wt} . \%$ phosphoric acid solution was used as the electrolyte solution. As shown in Supplementary

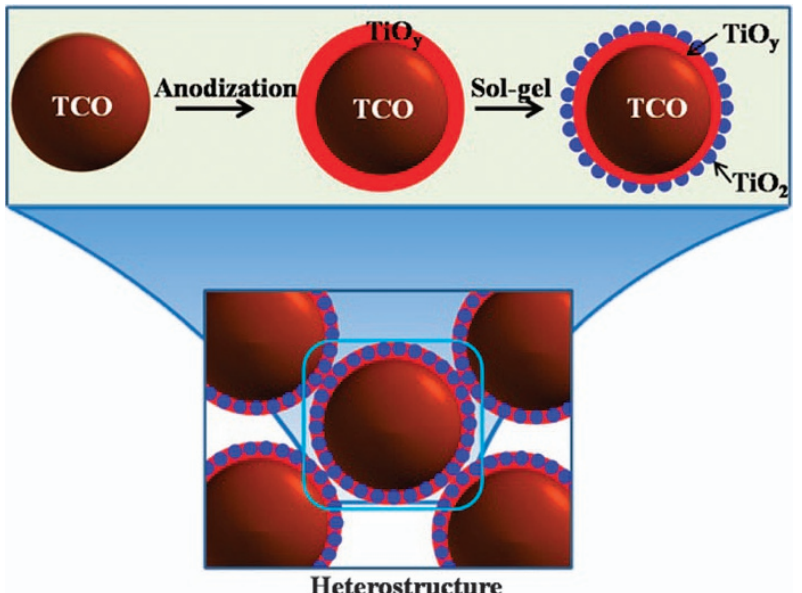

Scheme $1 \mathrm{~A}$ schematic representation of the synthesis of the heterostructured $\mathrm{TiC}_{1-\mathrm{x}} \mathrm{O}_{\mathrm{x}} @ \mathrm{TiO}_{\mathrm{y}}-\mathrm{TiO}_{2}$ bulks via the facile anodization process in assistance with the sol-gel chemical route.
Figure S1, anodization was realized in two steps: (i) constant current up to a certain voltage followed by (ii) anodization at a certain voltage for $5 \mathrm{~h}$. Then, the anodization pellets were grounded into powders, washed with deionized water several times and dried at $333 \mathrm{~K}$. The all-oxide $\mathrm{TiC}_{1-\mathrm{x}} \mathrm{O}_{\mathrm{x}} @ \mathrm{TiO}_{\mathrm{y}}-\mathrm{TiO}_{2}$ heterostructure materials were prepared by a facile anodization with the assistance of the sol-gel method, ${ }^{31}$ and then, the harvesting precursor powders were annealed at $1073 \mathrm{~K}$ for $2 \mathrm{~h}$ in a tubular resistance furnace under argon atmosphere. Finally, the synthesized $\mathrm{TiC}_{1-\mathrm{x}} \mathrm{O}_{\mathrm{x}} @ \mathrm{TiO}_{\mathrm{y}}-\mathrm{TiO}_{2}$ powders consolidated by SPS treatment were used to enhance the density of the materials, and the powders were placed in a graphite die with a $20-\mathrm{mm}$ diameter, heated to $1473 \mathrm{~K}$ at a rate of $100 \mathrm{~K} / \mathrm{min}$ and kept for 5 min under a pressure of $40 \mathrm{MPa}$ in vacuum. The sintered bulks were annealed at $1173 \mathrm{~K}$ for $10 \mathrm{~h}$ to eliminate the carbon on the surface. A series of all-oxide $\mathrm{TiC}_{1-\mathrm{x}} \mathrm{O}_{\mathrm{x}} @ \mathrm{TiO}_{\mathrm{y}}-\mathrm{TiO}_{2}$ heterostructure bulk materials were fabricated using these processes, as shown in Scheme 1.

The phase structure of all the samples was examined by X-ray diffraction (XRD) using $\mathrm{Cu} K \alpha$ radiation (D/max-2500). The morphology of the particles and ceramics were probed using a field-emission scanning electron microscope (FE-SEM, JEOL, 2011) and high-resolution transmission electron microscope (HRTEM, JEOL, 2011). Parallelepiped specimens with dimensions $3.0 \mathrm{~mm} \times$ $3.0 \mathrm{~mm} \times 14 \mathrm{~mm}$ cut from the disc-shaped samples were used for the measurements of the Seebeck coefficient and electrical conductivity, which were performed using the standard four-probe method (ULVAC-RIKO, ZEM-2) in a flowing He atmosphere. The thermal conductivity $(k)$ was calculated from $k=D C_{\mathrm{p}} d$, where $D$ is the thermal diffusivity coefficient measured by the laser flash method (TC9000, Ulvac-Riko, Japan) in vacuum in the temperature range from 300 to $973 \mathrm{~K}$, and the bulk density $(d)$ and porosity were obtained by the Archimedes method. The carrier concentration and mobility were measured using the Hall measurement system (PPMS-9T, Quantum Design Inc., USA) at $373 \mathrm{~K}$. The calculation procedures were performed using first principles based on the DFT method as implemented in the CASTEP package.

\section{RESULTS AND DISCUSSION}

\section{$\mathrm{TiC}_{0.5} \mathrm{O}_{0.5} @ \mathrm{TiO}_{\mathrm{y}}$ heterostructures}

A typical X-ray diffraction (XRD) pattern of the $\mathrm{TiC}_{0.5} \mathrm{O}_{0.5} @ \mathrm{TiO}_{\mathrm{y}}$ products prepared via the controllable anodization route using various voltages is shown in Figure 1a. Without the anodization, the singlephase $\mathrm{TiC}_{0.5} \mathrm{O}_{0.5}$ sample possesses a TiO-type structure. However, the other new phases with low intensity compared with that of $\mathrm{TiC}_{0.5} \mathrm{O}_{0.5}$, such as $\mathrm{Ti}_{2} \mathrm{O}_{3}$ and $\mathrm{Ti}_{3} \mathrm{O}_{5}$ (noted as $\mathrm{TiO}_{y}, 1<\mathrm{y}<2$ ), are generated in the $\mathrm{TiC}_{0.5} \mathrm{O}_{0.5}$ sample after $8-\mathrm{V}$ anodization, resulting in a $\mathrm{TiC}_{0.5} \mathrm{O}_{0.5} @ \mathrm{TiO}_{\mathrm{y}}$ composite with a small amount of $\mathrm{TiO}_{\mathrm{y}}$ phases.

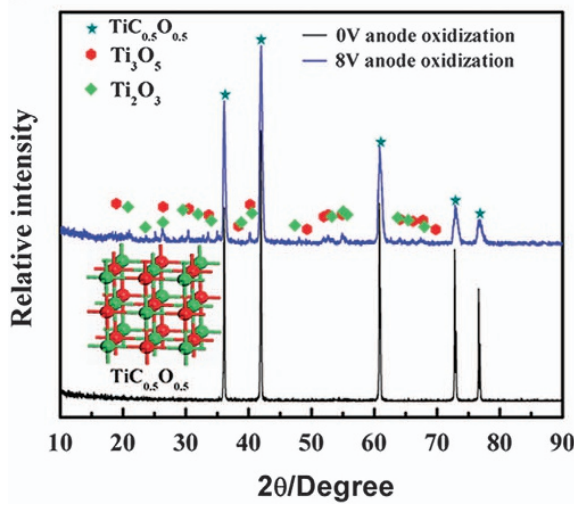

b

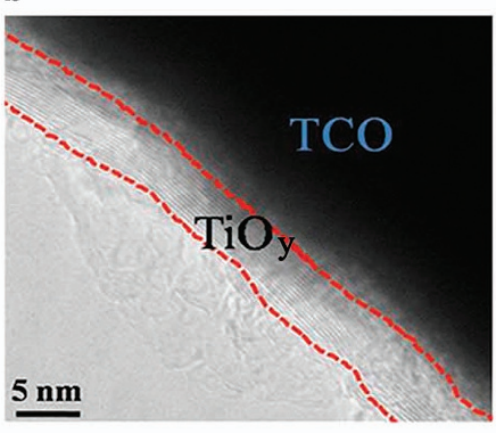

Figure 1 (a) XRD patterns of the $\mathrm{TiC}_{0.5} \mathrm{O}_{0.5}$ sample with $\mathrm{O}-\mathrm{V}$ and 8-V anodization; (b) TEM images of the $\mathrm{TiC}_{0.5} \mathrm{O}_{0.5} @ \mathrm{TiO}$ y heterostructures prepared via 8-V anodization. 
To confirm the surface microstructure of the $\mathrm{TiC}_{0.5} \mathrm{O}_{0.5} @ \mathrm{TiO}_{\mathrm{y}}$ composites, a transmission electron microscopy (TEM) image of the $\mathrm{TiC}_{0.5} \mathrm{O}_{0.5} @ \mathrm{TiO}_{\mathrm{y}}$ composite is presented in Figure 1b. Notably, a clear interface with a $5-10 \mathrm{~nm}$ thickness consisting predominantly of the $\mathrm{TiO}_{y}$ phases can be observed on the surface of the $\mathrm{TiC}_{0.5} \mathrm{O}_{0.5}$ particles prepared via $8-\mathrm{V}$ anodization, which is consistent with the XRD analysis. These results provide strong evidence that $\mathrm{TiC}_{0.5} \mathrm{O}_{0.5} @ \mathrm{TiO}_{\mathrm{y}}$ heterojunctions with core-shell structure were fabricated via a facile anodization process.

The temperature dependence of the electrical transport properties for the $\mathrm{TiC}_{0.5} \mathrm{O}_{0.5} @ \mathrm{TiO}_{\mathrm{y}}$ samples prepared by various anodization voltages between 300 and $1000 \mathrm{~K}$ are plotted in Figure 2. All the samples exhibit a semiconducting behavior with relatively high electrical conductivity of the order $10^{2} \mathrm{~S} \mathrm{~cm}^{-1}$ in the range between 300 and $1000 \mathrm{~K}$, as presented in Figure 2a, and the increased electrical conductivity with temperature suggests a transition from extrinsic to intrinsic behavior, similarly to $\mathrm{TiO}_{2-\mathrm{x}}$ materials. ${ }^{26,41,42}$ The electrical conductivities of the $\mathrm{TiC}_{0.5} \mathrm{O}_{0.5}$ samples prepared using $0,5,8$ and $10 \mathrm{~V}$ anodization at $973 \mathrm{~K}$ are $\sim 1074, \sim 731, \sim 682$ and $\sim 621 \mathrm{~S} \mathrm{~cm}^{-1}$, respectively. The decrease of the electrical conductivity of the $\mathrm{TiC}_{0.5} \mathrm{O}_{0.5} @ \mathrm{TiO}_{\mathrm{y}}$ heterostructured samples should result from the decreased density of carriers. In addition, the Seebeck coefficients for all the $\mathrm{TiC}_{0.5} \mathrm{O}_{0.5} @ \mathrm{TiO}_{\mathrm{y}}$ heterostructured samples are negative over the entire temperature range, as observed in Figure $2 \mathrm{~b}$, which is indicative of n-type electrical transport property. The Seebeck coefficient follows a nearly linear temperature dependence up to $973 \mathrm{~K}$, and the absolute values of the Seebeck coefficient are approximately 16, 68, 73 and

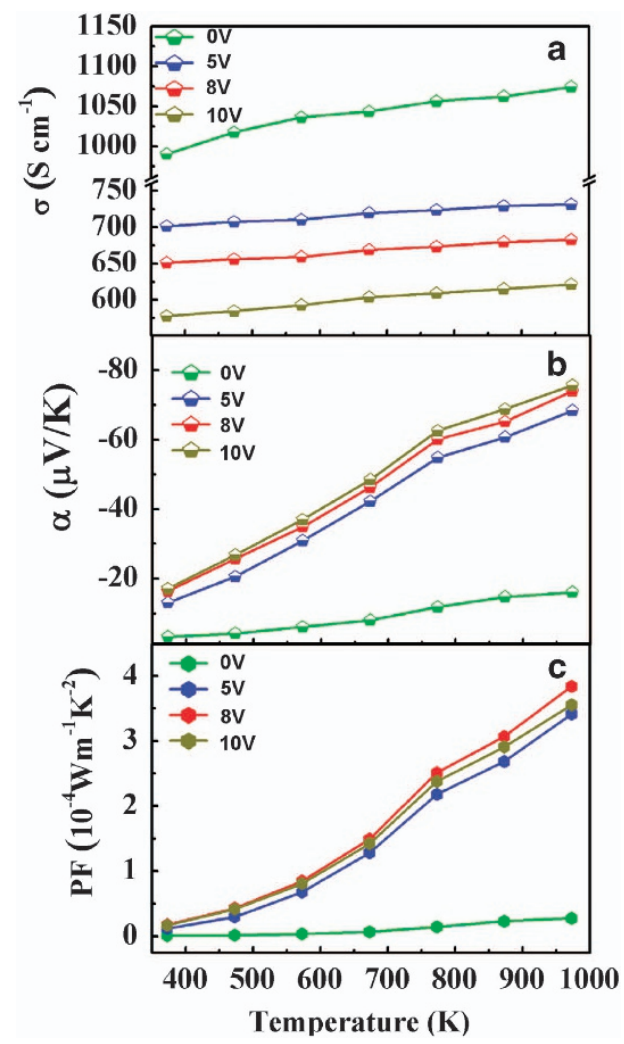

Figure 2 The temperature dependence of the electrical transport properties of the $\mathrm{TiC}_{0.5} \mathrm{O}_{0.5} @ \mathrm{TiO}_{\mathrm{y}}$ samples with various anodization processes. Plots of the (a) electrical conductivity, $\sigma$; (b) Seebeck coefficient, $\alpha$; and (c) thermal conductivity, $k$.
$76 \mu \mathrm{V} / \mathrm{K}$ at $973 \mathrm{~K}$ for the $\mathrm{TiC}_{0.5} \mathrm{O}_{0.5} @ \mathrm{TiO}_{\mathrm{y}}$ heterostructures achieved by $0,5,8$ and $10 \mathrm{~V}$ anodization, respectively. ${ }^{43}$ The monotonous increase in the absolute Seebeck coefficient and decrease in the electrical conductivity with increasing anodization voltage can be attributed to core-shell $\mathrm{TiC}_{0.5} \mathrm{O}_{0.5} @ \mathrm{TiO}_{\mathrm{y}}$ heterostructured interfaces with $\mathrm{TiO}_{\mathrm{y}}$ barriers, where the barrier can act as an energy barrier to substantially scatter low-energy carriers; thus, high-energy electrons that conduct better can overcome the $\mathrm{TiO}_{\mathrm{y}}$ barrier rather than the relatively low-energy ones. ${ }^{33,41,44}$ This phenomenon can be confirmed by the decrease in the carrier concentration $(n)$ observed in Table 1; it is apparent that the carrier concentration decreases from $3.3 \times 10^{21} \mathrm{~cm}^{-3}$ for the $\mathrm{TiC}_{0.5} \mathrm{O}_{0.5}$ sample to $2.47 \times 10^{21} \mathrm{~cm}^{-3}$ for the $\mathrm{TiC}_{0.5} \mathrm{O}_{0.5} @ \mathrm{TiO}_{\mathrm{y}}$ heterostructures at $373 \mathrm{~K}$; in addition, the carrier mobility correspondingly decreases from $1.87 \mathrm{~cm}^{-2} \mathrm{~V}^{-1} \mathrm{~S}^{-1}$ for the $\mathrm{TiC}_{0.5} \mathrm{O}_{0.5}$ sample to $1.65 \mathrm{~cm}^{-2} \mathrm{~V}^{-1} \mathrm{~S}^{-1}$ for the $\mathrm{TiC}_{0.5} \mathrm{O}_{0.5} @ \mathrm{TiO}_{\mathrm{y}}$ heterostructures. Compared with the $\mathrm{TiC}_{0.5} \mathrm{O}_{0.5}$ sample, the $\mathrm{TiC}_{0.5} \mathrm{O}_{0.5} @ \mathrm{TiO}_{\mathrm{y}}$ heterostructures prepared by the facile anodization process achieve optimized electrical performance and improved thermoelectric properties. The calculated power factor $\left(P F=\alpha^{2} \sigma\right)$ values of all the samples are presented in Figure 2c. Note that the $\mathrm{TiC}_{0.5} \mathrm{O}_{0.5} @ \mathrm{TiO}_{\mathrm{y}}$ samples exhibit higher power factor values over the entire temperatures range because of the higher Seebeck coefficient compared with that of the $\mathrm{TiC}_{0.5} \mathrm{O}_{0.5}$ sample, and the largest thermoelectric power factor of the $\mathrm{TiC}_{0.5} \mathrm{O}_{0.5} @ \mathrm{TiO}_{\mathrm{y}}$ samples achieved by $0-, 5-, 8-$ and $10-\mathrm{V}$ anodization at $973 \mathrm{~K}$ are $0.28 \times 10^{-4}$, $3.4 \times 10^{-4}, 3.8 \times 10^{-4}$, and $3.6 \times 10^{-4} \mathrm{~W} \mathrm{~m}^{-1} \mathrm{~K}^{-2}$, respectively. Although an increase in the power factor can be achieved, there is room to further enhance the TE performance. To obtain a higher Seebeck coefficient, $\mathrm{TiO}_{2}$ can be introduced to form $\mathrm{TiC}_{0.5} \mathrm{O}_{0.5} @ \mathrm{TiO}_{\mathrm{y}^{-}}$ $\mathrm{TiO}_{2}$ heterostructures to enhance the thermoelectric properties.

\section{$\mathrm{TiC}_{0.5} \mathrm{O}_{0.5} @ \mathrm{TiO}_{\mathrm{y}}-\mathrm{TiO}_{2}$ heterostructures}

After coating the $\mathrm{TiO}_{2}$ nanoparticles on the $\mathrm{TiC}_{0.5} \mathrm{O}_{0.5} @ \mathrm{TiO}_{\mathrm{y}}$ heterostructures via facile anodization assisted by the sol-gel chemical route, representative TEM images and $\mathrm{XRD}$ analysis of the $\mathrm{TiC}_{0.5} \mathrm{O}_{0.5} @ \mathrm{TiO}_{\mathrm{y}^{-}}$ $5 \mathrm{wt} . \% \mathrm{TiO}_{2}$ composite are presented in Figure 3 and Supplementary Figure S2, respectively. According to the XRD pattern of the $\mathrm{TiC}_{0.5} \mathrm{O}_{0.5} @ \mathrm{TiO}_{\mathrm{y}}-5 \mathrm{wt} . \% \mathrm{TiO}_{2}$ composite, a new major phase, except for the $\mathrm{TiC}_{0.5} \mathrm{O}_{0.5}$ and $\mathrm{TiO}_{\mathrm{y}}$ phases, is observed in Supplementary Figure S2, and the large intensity of the $\mathrm{TiO}_{2}$ phase with the plane (110) at the $2 \theta=27.3^{\circ}$ diffraction angle indicates that the $\mathrm{TiO}_{2}$ phase can transform into the rutile structure, exhibiting low thermal conductivity after being annealed for $3 \mathrm{~h}$ at $1073 \mathrm{~K}$. Moreover, analysis of the TEM images in Figure $3 \mathrm{a}$ and $\mathrm{c}$ reveals that $\mathrm{TiO}_{2}$ nanoparticles with an average particle size of approximately $20 \mathrm{~nm}$ are homogeneously dispersed on the surface of the $\mathrm{TiC}_{0.5} \mathrm{O}_{0.5} @ \mathrm{TiO}_{\mathrm{y}}$ heterostructures. To further confirm the phase of the $\mathrm{TiO}_{2}$ nanoparticles, the HRTEM image in Figure 3d shows that the $\mathrm{TiO}_{2}$ nanoparticle is a cluster of the plane (110) with a lattice spacing of $3.25 \AA$. According to the XRD and TEM results, the powders are composed of $\mathrm{TiC}_{0.5} \mathrm{O}_{0.5}$, $\mathrm{TiO}_{\mathrm{y}}$ and $\mathrm{TiO}_{2}$ phases.

Furthermore, typical TEM images of the $\mathrm{TiC}_{0.5} \mathrm{O}_{0.5} @ \mathrm{TiO}_{\mathrm{y}}-5 \mathrm{wt} . \%$ $\mathrm{TiO}_{2}$ heterostructured bulk after SPS treatment using the obtained $\mathrm{TiC}_{0.5} \mathrm{O}_{0.5} @ \mathrm{TiO}_{\mathrm{y}}-5 \mathrm{wt} . \% \mathrm{TiO}_{2}$ powder composites are presented in Figure 4. The TEM image with low magnification reveals a bright nanoscale interface layer between the $\mathrm{TiC}_{0.5} \mathrm{O}_{0.5}$ matrixes in Figure $4 \mathrm{a}$. At high magnification, as observed in Figure $4 \mathrm{~b}$ and $c$, the sample contains an obvious interface layer composed of the $\mathrm{TiO}_{\mathrm{y}}-\mathrm{TiO}_{2}$ heterostructures with bright contrast and a layer thickness of $30-40 \mathrm{~nm}$ in the $\mathrm{TiC}_{0.5} \mathrm{O}_{0.5} @ \mathrm{TiO}_{\mathrm{y}}-5 \mathrm{wt} . \% \mathrm{TiO}_{2}$ heterostructured bulk, where the single-crystalline rutile-phase $\mathrm{TiO}_{2}$ nanoparticles can be 
Table 1 Electrical conductivity $(\sigma)$, carrier concentration $(n)$ and mobility $(\mu)$ of the samples at $300 \mathrm{~K}$

\begin{tabular}{lccc}
\hline Samples & anodization (OV) & anodization (8V) & anodization (8 V) and coating content of TiO 2 (5wt.\%) $^{\circ}$ \\
\hline$\sigma\left(\mathrm{S} \mathrm{cm}^{-1}\right)$ & 990 & 651 & 180 \\
$\mathrm{n}\left(10^{21} \mathrm{~cm}^{-3}\right)$ & 3.30 & 2.47 & 0.86 \\
$\mu\left(\mathrm{cm}^{-2} \mathrm{~V}^{-1} \mathrm{~S}^{-1}\right)$ & 1.87 & 1.65 & 1.42 \\
\hline
\end{tabular}

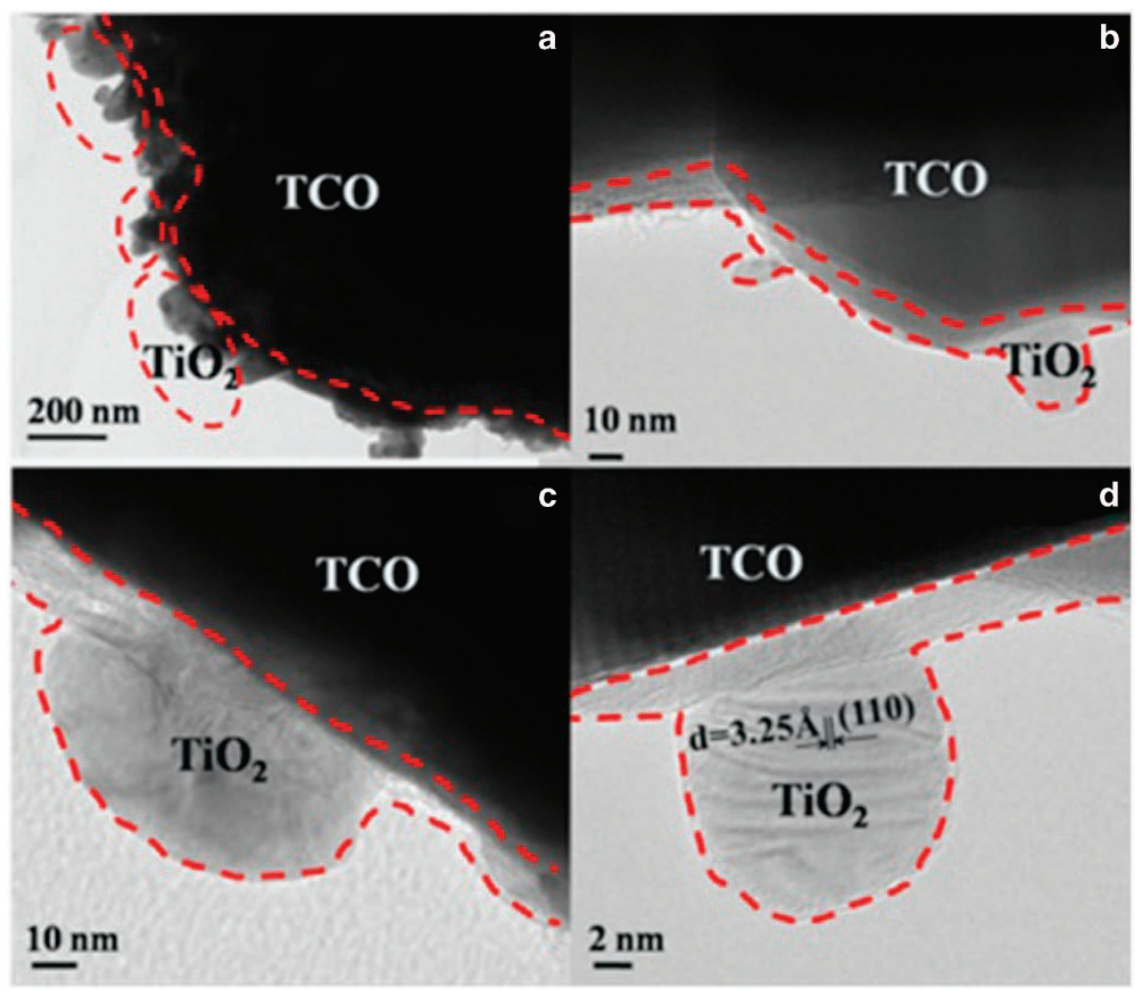

Figure $3 \mathrm{TEM}$ images of $\mathrm{TiC}_{0.5} \mathrm{O}_{0.5} @ \mathrm{TiO}_{\mathrm{y}}-\mathrm{TiO}_{2}$ heterostructured powders prepared via 8-V anodization with different magnification (a-d).

dispersed into the inner part of the $\mathrm{TiO}_{\mathrm{y}}$ shell. Figure $4 \mathrm{~d}$ and $\mathrm{e}$ in assistance with the SAED diffraction patterns in Figure $4 \mathrm{f}$ and $\mathrm{g}$ highlights HRTEM images of the $\mathrm{TiC}_{0.5} \mathrm{O}_{0.5}$ matrix and $\mathrm{TiO}_{2}$ nanoparticle, respectively. The distances between the lattice fringes of the $\mathrm{TiC}_{0.5} \mathrm{O}_{0.5}$ matrix and rutile-phase $\mathrm{TiO}_{2}$ nanoparticles can be assigned to the interplanar distance of $\mathrm{TiC}_{0.5} \mathrm{O}_{0.5}$ (200) and rutile $\mathrm{TiO}_{2}$ (110), corresponding to $d_{200}=2.12 \AA$ and $d_{101}=3.25 \AA$, respectively. This finding implies that the ideal heterostructures can be formed in the $\mathrm{TiC}_{0.5} \mathrm{O}_{0.5} @ \mathrm{TiO}_{\mathrm{y}}-\mathrm{TiO}_{2}$ bulk. Overall, the $\mathrm{TiC}_{0.5} \mathrm{O}_{0.5} @ \mathrm{TiO}_{\mathrm{y}}-\mathrm{TiO}_{2}$ heterostructures can be reassembled after SPS treatment.

The temperature dependence of the thermoelectric properties for the various $\mathrm{TiC}_{0.5} \mathrm{O}_{0.5} @ \mathrm{TiO}_{\mathrm{y}}-\mathrm{TiO}_{2}$ heterostructured bulks is shown in Figure 5. As observed in Figure 5a, compared with that of the $\mathrm{TiC}_{0.5} \mathrm{O}_{0.5} @ \mathrm{TiO}_{\mathrm{y}}$ heterostructures, the electrical conductivity of the $\mathrm{TiC}_{0.5} \mathrm{O}_{0.5} @ \mathrm{TiO}_{\mathrm{y}}-\mathrm{TiO}_{2}$ heterostructures can prove to be drastically reduced to lower values $\left(403 \mathrm{~S} \mathrm{~cm}^{-1-} 669 \mathrm{~S} \mathrm{~cm}^{-1}\right)$ in the entire measured temperature range. In addition, the values decrease with the coating content of the $\mathrm{TiO}_{2}$ nanoparticles and voltage of the anodization process, with the most reduced value of $669 \mathrm{~S} \mathrm{~cm}^{-1}$ for the $\mathrm{TiC}_{0.5} \mathrm{O}_{0.5} @ \mathrm{TiO}_{\mathrm{y}}-1 w \mathrm{wt} . \% \mathrm{TiO}_{2}$ heterostructured sample at $973 \mathrm{~K}$. The Seebeck coefficients between 373 and $973 \mathrm{~K}$ are shown in Figure 5b. The absolute value of the Seebeck coefficient $(\alpha)$ has a weak temperature dependence, with a maximum at high temperature. Remarkably, the $\mathrm{TiC}_{0.5} \mathrm{O}_{0.5} @ \mathrm{TiO}_{\mathrm{y}}-\mathrm{TiO}_{2}$ heterostructured bulks can result in a great increase in the absolute value of the Seebeck coefficient compared with that of the $\mathrm{TiC}_{0.5} \mathrm{O}_{0.5} @ \mathrm{TiO}_{\mathrm{y}}$ heterostructures, and the absolute value of the $\mathrm{TiC}_{0.5} \mathrm{O}_{0.5} @ \mathrm{TiO}_{\mathrm{y}}-\mathrm{TiO}_{2}$ heterostructures with $8-\mathrm{V}$ anodization increases from 105 to $156 \mu \mathrm{V} / \mathrm{K}$ with the coating amount of $\mathrm{TiO}_{2}$ nanoparticles from $1 \mathrm{wt} . \%$ to $8 \mathrm{wt} . \%$, respectively. Notably, the absolute $\alpha$ value for the $\mathrm{TiC}_{0.5} \mathrm{O}_{0.5} @ \mathrm{TiO}_{\mathrm{y}^{-}}$ $5 \mathrm{wt} . \% \mathrm{TiO}_{2}$ heterostructures increases from 146 to $156 \mu \mathrm{V} / \mathrm{K}$ for anodization voltages from 5 to $8 \mathrm{~V}$ at $973 \mathrm{~K}$, respectively. The decrease in the electrical conductivity and increase in the absolute value of the Seebeck coefficient can be explained by the carrier double-barrier effect of the core-shell $\mathrm{TiC}_{0.5} \mathrm{O}_{0.5} @ \mathrm{TiO}_{\mathrm{y}}-\mathrm{TiO}_{2}$ bulks on the carrier concentration and carrier mobility. ${ }^{37,39,41}$ The decrease in the electrical conductivity and increase in the Seebeck coefficient can result from the double-barrier filtering effect of the $\mathrm{TiC}_{0.5} \mathrm{O}_{0.5} @ \mathrm{TiO}_{\mathrm{y}}-\mathrm{TiO}_{2}$ bulks on blocking the low-energy carriers in the $\mathrm{TiO}_{\mathrm{y}}-\mathrm{TiO}_{2}$ barrier, as observed in Table 1, and the carrier concentration decreases from $2.47 \times 10^{21} \mathrm{~cm}^{-3}$ for the $\mathrm{TiC}_{0.5} \mathrm{O}_{0.5} @ \mathrm{TiO}_{\mathrm{y}}$ bulks to $0.86 \times 10^{21} \mathrm{~cm}^{-3}$ for the sample containing $5 \mathrm{wt} . \% \mathrm{TiO}_{2}$ at $333 \mathrm{~K}$. Consequently, the high-energy electrons can be conducted better and the Seebeck coefficients can be increased, ${ }^{34}$ which is similar to a previous report on $\mathrm{SrTiO}_{3} / \mathrm{SrTi}_{0.8} \mathrm{Nb}_{0.2} \mathrm{O}_{3} / \mathrm{SrTiO}_{3}$ with a huge Seebeck coefficient. ${ }^{45}$ The mostly positive temperature dependence of the electrical conductivity and the absolute value of the Seebeck coefficient cause the power factor $\left(P F=S^{2} \sigma\right)$ to increase markedlyat high temperature, as 


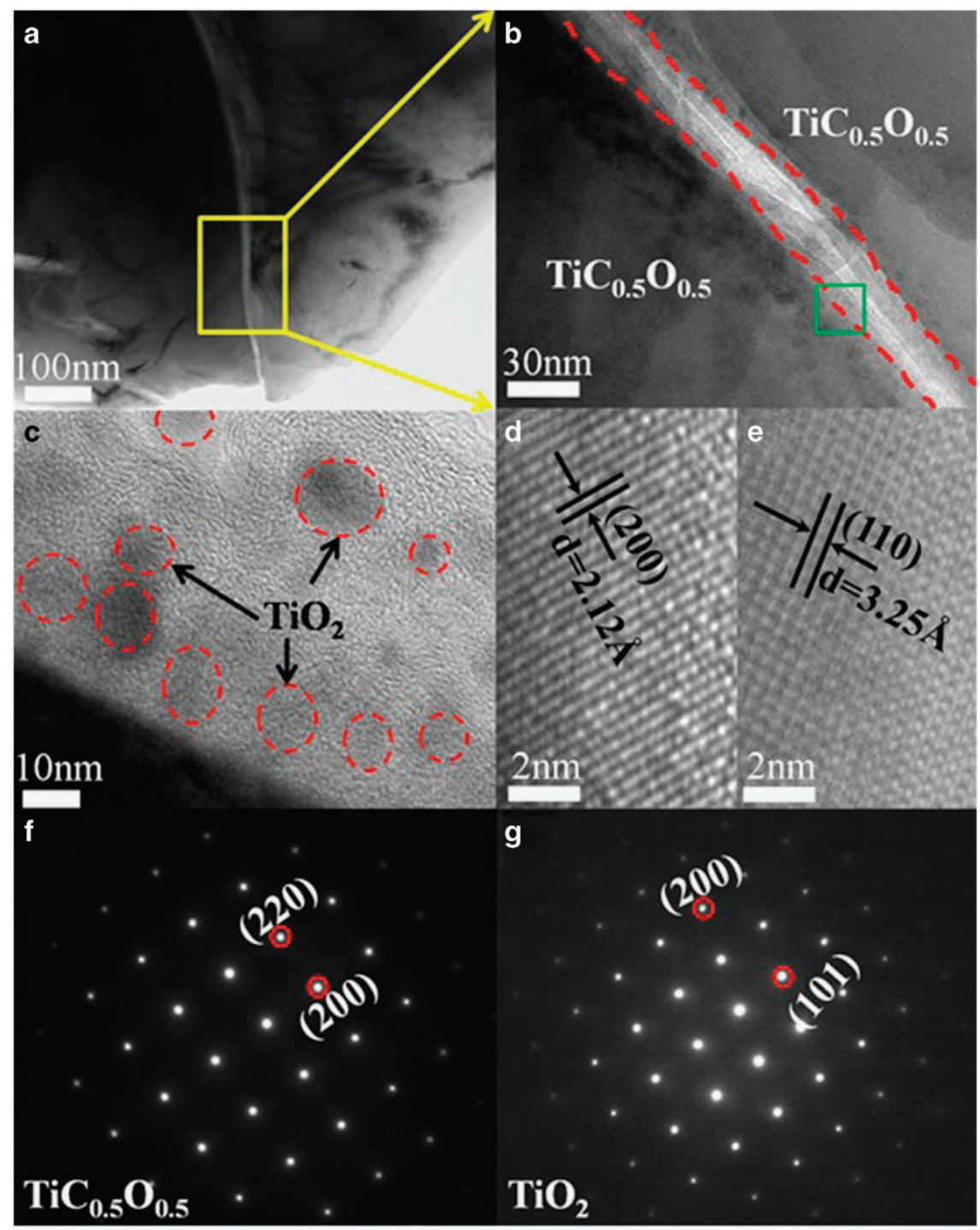

Figure $4 \mathrm{TEM}$ photographs of the all-oxide $\mathrm{TiC}_{0.5} \mathrm{O}_{0.5} @ \mathrm{TiO}_{\mathrm{y}}-\mathrm{TiO}_{2}$ heterostructures with 8-V anodization after SPS treatment: (a) TEM image of $\mathrm{TiC}_{0.5} \mathrm{O}_{0.5} @ \mathrm{TiO}_{\mathrm{y}}-\mathrm{TiO}_{2}$ particles after SPS treatment; (b) high-magnification TEM image of the yellow rectangle area in (a); (c) high-magnification TEM image of the green rectangle area in (b); (d, e) high-magnification TEM images of $\mathrm{TiC}_{0.5} \mathrm{O}_{0.5}$ and $\mathrm{TiO}_{2}$, respectively; (f, g) SAED diffraction pattern of (d) and (e), respectively.

displayed in Supplementary Figure S3, achieving the highest power factor of $10.34 \times 10^{-4} \mathrm{~W} \mathrm{~m}^{-1} \mathrm{~K}^{-2}$ at $973 \mathrm{~K}$ for the $\mathrm{TiC}_{0.5} \mathrm{O}_{0.5} @ \mathrm{TiO}_{\mathrm{y}^{-}}$ $5 \mathrm{wt} . \% \mathrm{TiO}_{2}$ bulks with $8-\mathrm{V}$ anodization, which is larger than that of $\mathrm{TiO}_{1.83}$ and $\mathrm{Ti}(\mathrm{O}, \mathrm{N}) .^{26,28}$

The thermal conductivities as a function of temperature for the $\mathrm{TiC}_{0.5} \mathrm{O}_{0.5} @ \mathrm{TiO}_{\mathrm{y}}-\mathrm{TiO}_{2}$ bulks are displayed in Figure 5c. The thermal conductivity increases from $\sim 1.1$ to $\sim 1.8 \mathrm{~W} \mathrm{~m}^{-1} \mathrm{~K}^{-1}$ from 373 to $973 \mathrm{~K}$, which is close to the behavior of $\mathrm{Ti}(\mathrm{O}, \mathrm{N})$ and $\mathrm{TiO}_{2}$ thin films below $1.7 \mathrm{~W} \mathrm{~m}^{-1} \mathrm{~K}^{-1}$ but lower than that of $\mathrm{TiO}_{x}$ and $\mathrm{TiO}_{1.1} .{ }^{26-28,46}$ Furthermore, the thermal conductivity of the $\mathrm{TiC}_{0.5} \mathrm{O}_{0.5} @ \mathrm{TiO}_{\mathrm{y}}-5 \mathrm{wt} . \%$ $\mathrm{TiO}_{2}$ bulk prepared via $8-\mathrm{V}$ anodization increases from $\sim 1.1$ to $\sim 1.4$ $\mathrm{W} \mathrm{m}{ }^{-1} \mathrm{~K}^{-1}$ from 373 to $973 \mathrm{~K}$. The lattice thermal conductivity $k_{\mathrm{L}}$ was estimated by directly subtracting the electronic thermal conductivity $\kappa_{e}$ from the total thermal conductivity $k$ (the calculation details are provided in Supplementary Information). To further understand the low $k_{\mathrm{L}}$, the phonon mean free path (MFP) was estimated for a representative sample $8 \mathrm{~V}+5 \mathrm{wt} . \% \% \mathrm{TiO}_{2}$ (the calculation details are provided in Supplementary Information). This material was observed to exhibit a relatively large average sound velocity $(\sim 4922 \mathrm{~m} / \mathrm{s})$ and a small MFP $(\sim 0.2 \mathrm{~nm})$. The large sound velocity provides direct evidence of a large bulk modulus, indicating rigid and hard bonding in a TCO matrix, which is not commonly observed in good thermoelectric materials. The small MFP is on the order of atomic distance, suggesting very intensive phonon scattering. A couple of explanations can be provided for the low thermal conductivity: (i) the heterostructured interfaces act as scattering centers against phonons, leading to an ultra-small MFP in the $\mathrm{TiC}_{0.5} \mathrm{O}_{0.5} @ \mathrm{TiO}_{\mathrm{y}}-\mathrm{TiO}_{2}$ bulks and ${ }^{33,47-50}$ (ii) the rutile-structure $\mathrm{TiO}_{2}$ phase prepared by sol-gel method assistance with annealing at $1073 \mathrm{~K}$ and a small amount of the amorphous $\mathrm{TiO}_{2}$ phase obtained by SPS sintering can reduce the thermal conductivity. ${ }^{51}$ These results clearly demonstrate that the heterostructured interface scattering is very important in reducing the total thermal conductivity of thermoelectric materials. ${ }^{27,52,53}$ The dimensionless figure of merit $(Z T)$ is calculated in Figure $5 \mathrm{~d}$. The results indicate that the $\mathrm{TiC}_{0.5} \mathrm{O}_{0.5} @ \mathrm{TiO}_{\mathrm{y}}-\mathrm{TiO}_{2}$ heterostructures can significantly enhance the thermoelectric performance at high 

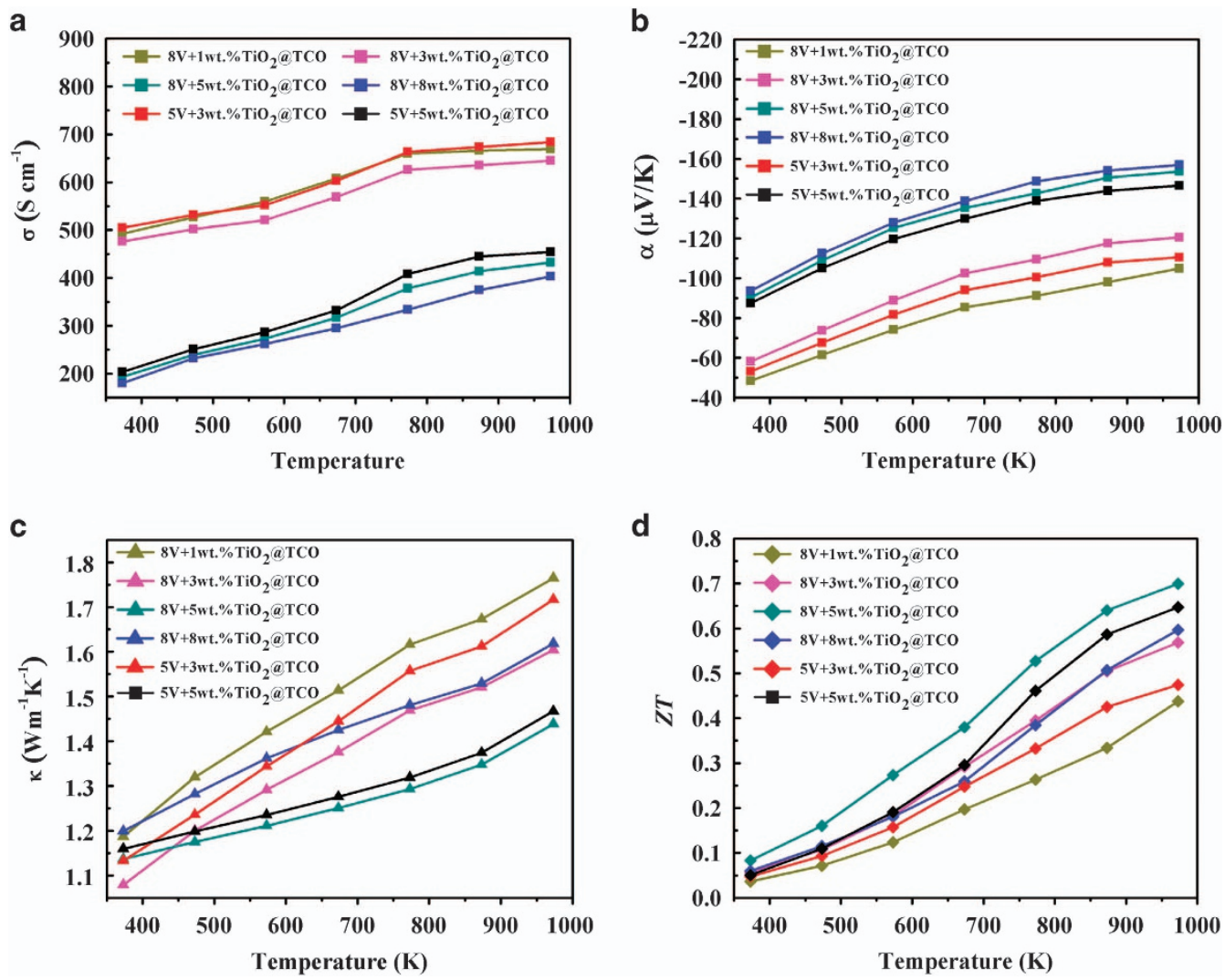

Figure 5 The temperature dependence of the thermoelectric performance for various $\mathrm{TiC}_{0.5} \mathrm{O}_{0.5} @ \mathrm{TiO}_{\mathrm{y}}-\mathrm{TiO}_{2}$ samples. Plots of the (a) electrical conductivity, $\sigma$; (b) Seebeck coefficient, $\alpha$; (c) thermal conductivity, $k$; and (d) figure of merit, $Z T$.

temperature because of the increase in the Seebeck coefficient and reduction in the thermal conductivity, corresponding to a maximum $Z T$ value of $\sim 0.7$ for the $\mathrm{TiC}_{0.5} \mathrm{O}_{0.5} @ \mathrm{TiO}_{\mathrm{y}}-5 \mathrm{wt} . \% \mathrm{TiO}_{2}$ bulk with $8-\mathrm{V}$ anodization at $973 \mathrm{~K}$ (Supplementary Figures S5 and S6), which is two times greater than that of $\mathrm{TiC}_{0.5} \mathrm{O}_{0.5} @ 15 \mathrm{wt} . \% \mathrm{TiO}_{2}$ at $873 \mathrm{~K}^{31}$ Given the effect of the solid solution level of the $\mathrm{TiC}_{1-\mathrm{x}} \mathrm{O}_{\mathrm{x}}$ on the thermoelectric properties, a series of $\mathrm{TiC}_{1-\mathrm{x}} \mathrm{O}_{\mathrm{x}} @ \mathrm{TiO}_{\mathrm{y}}-\mathrm{TiO}_{2}$ heterostructures were constructed to achieve enhanced thermoelectric performance.

\section{$\mathrm{TiC}_{1-\mathrm{x}} \mathrm{O}_{\mathrm{x}} @ \mathrm{TiO}_{\mathrm{y}}-\mathrm{TiO}_{2}$ heterostructures}

To further improve the TE performance of the $\mathrm{TiC}_{0.5} \mathrm{O}_{0.5} @ \mathrm{TiO}_{\mathrm{y}}-\mathrm{TiO}_{2}$ heterostructures, $\mathrm{TiC}_{1-\mathrm{x}} \mathrm{O}_{\mathrm{x}} @ \mathrm{TiO}_{\mathrm{y}}-\mathrm{TiO}_{2}$ heterostructures were investigated. The XRD patterns of various solid solution levels of $\mathrm{TiC}_{1-\mathrm{x}} \mathrm{O}_{\mathrm{x}}$ are presented in Supplementary Figure S4, and the peak position for each diffraction of the plane shifts slightly toward lower angles upon increasing the carbon content, which is consistent with previous work. ${ }^{54}$ To verify the microstructure of the fractographs of the $\mathrm{TiC}_{1-\mathrm{x}} \mathrm{O}_{\mathrm{x}} @ \mathrm{TiO}_{\mathrm{y}}-\mathrm{TiO}_{2}$ bulks after SPS treatment, SEM images of the $\mathrm{TiC}_{1-\mathrm{x}} \mathrm{O}_{\mathrm{x}} @ \mathrm{TiO}_{\mathrm{y}}-5 \mathrm{wt} . \% \mathrm{TiO}_{2}$ bulks with 8-V anodization are displayed in Supplementary Figure S7. The images of all the bulks clearly show that the porosity increases with increasing carbon content, which is consistent with the image in Supplementary Figure S8. Furthermore, the porosity of all the bulks is below $5 \%$, indicating that dense bulks can be achieved by the SPS method.

The temperature dependence of the electrical conductivity, Seebeck coefficient, thermal conductivity and $Z T$ for the $\mathrm{TiC}_{1-\mathrm{x}} \mathrm{O}_{\mathrm{x}} @ \mathrm{TiO}_{\mathrm{y}}-5 \mathrm{wt}$. $\% \mathrm{TiO}_{2}(x=0.6,0.7,0.8,0.9,1)$ bulks with $8-\mathrm{V}$ anodization are plotted in Figure 6. The electrical conductivity in Figure $6 \mathrm{a}$ increases with temperature, with a maximum value of $540 \mathrm{~S} \mathrm{~cm}^{-1}$ at $973 \mathrm{~K}$ for the $x=0.9$ sample. In addition, the electrical conductivity of the $\mathrm{TiC}_{1-\mathrm{x}}$ $\mathrm{O}_{\mathrm{x}} @ \mathrm{TiO}_{\mathrm{y}}-5 \mathrm{wt} . \% \mathrm{TiO}_{2}$ bulks, except for the ( $\mathrm{TiO} @ \mathrm{TiO}_{\mathrm{y}}-5 \mathrm{wt} . \% \mathrm{TiO}_{2}$ ) sample, increases from 475 to $540 \mathrm{~S} \mathrm{~cm}^{-1}$ with $x$ ranging from 0.6 to 0.9 at $973 \mathrm{~K}$, which is higher than that of $\mathrm{TiC}_{0.5} \mathrm{O}_{0.5} @ \mathrm{TiO}_{\mathrm{y}}-5 \mathrm{wt} . \% \mathrm{TiO}_{2}$ bulks. This result may be attributed to the effect of the porosity of the $\mathrm{TiC}_{1-\mathrm{x}} \mathrm{O}_{\mathrm{x}} @ \mathrm{TiO}_{\mathrm{y}}-5 \mathrm{wt} . \% \mathrm{TiO}_{2}$ bulks on the overall TE performance, which can be deteriorated because the electrical conductivity can be decreased dramatically because of the increased electrons scattered by enormous pores. ${ }^{55}$ However, the electrical conductivity of the bulk ( $\mathrm{TiO} @ \mathrm{TiO}_{\mathrm{y}}-5 \mathrm{wt} . \% \mathrm{TiO}_{2}$ ) can decrease because reactions such as $\mathrm{TiO}$ $+\mathrm{Ti}_{3} \mathrm{O}_{5}=2 \mathrm{Ti}_{2} \mathrm{O}_{3}$ and $\mathrm{TiO}+\mathrm{TiO}_{2}=\mathrm{Ti}_{2} \mathrm{O}_{3}$ in the $\mathrm{TiO} @ \mathrm{TiO}_{\mathrm{y}}-5 w \mathrm{w} . \%$ $\mathrm{TiO}_{2}$ system can destroy the heterostructures such that the thermoelectric performance can be reduced. The Seebeck coefficients for the $\mathrm{TiC}_{1-\mathrm{x}} \mathrm{O}_{\mathrm{x}} @ \mathrm{TiO}_{\mathrm{y}}-5 \mathrm{wt} . \% \mathrm{TiO}_{2}$ bulks with 8-V anodization are shown in Figure $6 \mathrm{~b}$, and the dominant charge carrier of those samples remains the electron, as indicated by the negative sign of the Seebeck coefficient. Importantly, the absolute values for all the samples increase with temperature, and the highest value of $162 \mu \mathrm{V} / \mathrm{K}$ can be obtained in the $\mathrm{TiC}_{0.1} \mathrm{O}_{0.9} @ \mathrm{TiO}_{\mathrm{y}}-5 \mathrm{wt} . \% \mathrm{TiO}_{2}$ bulk at $973 \mathrm{~K}$. In addition, the Seebeck coefficient of all the bulks, except for TiO@ $\mathrm{TiO}_{\mathrm{y}}-5 \mathrm{wt} . \% \mathrm{TiO}_{2}$, can be improved from 152 to $162 \mu \mathrm{V} / \mathrm{K}$ by increasing $x$ from 0.6 to 0.9 at $973 \mathrm{~K}$. The enhanced Seebeck coefficient may originate from two aspects: (i) the above-mentioned heterostructures and (ii) the effect of the total density of states (DOS) varying with the core $\mathrm{TiC}_{1-\mathrm{x}} \mathrm{O}_{\mathrm{x}}$. The energy around the Fermi energy $E_{F}$ increases with $x$, as demonstrated in Figure $7 \mathrm{a}$ and $\mathrm{b}$. Furthermore, the effect of this local increase in DOS on the Seebeck coefficient is 
a

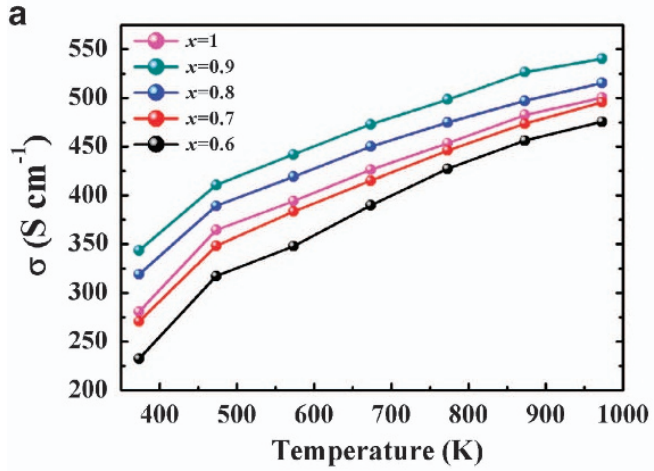

C

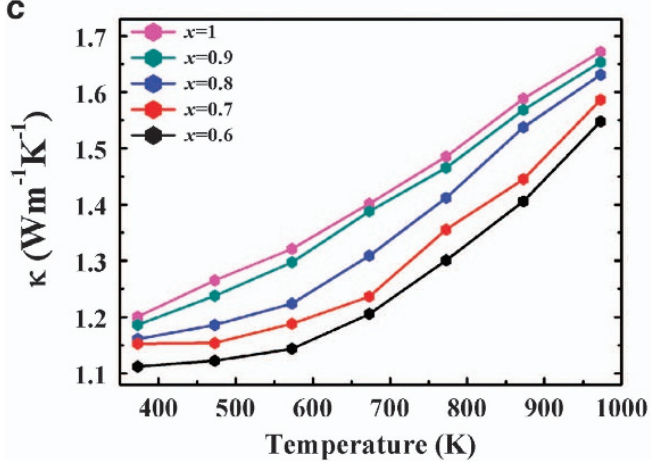

b

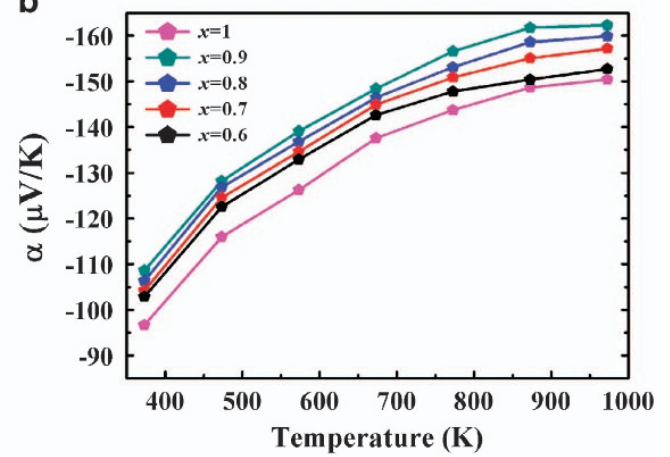

d

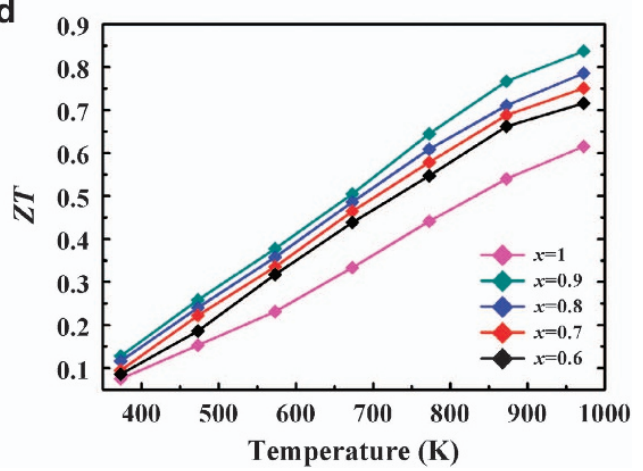

Figure 6 The temperature dependence of the electrical transport properties for $\mathrm{TiC}_{1-\mathrm{x}} \mathrm{O}_{\mathrm{x}} @ \mathrm{TiO}_{\mathrm{y}}-5 \mathrm{wt} . \% \mathrm{TiO}_{2}$ with 8-V anodization samples: (a) electrical conductivity, $\sigma$; (b) Seebeck coefficient, $\alpha$; (c) thermal conductivity, $\kappa$; and (d) figure of merit, $Z T$.

given by the Mott expression: ${ }^{56}$

$$
\alpha=\left.\frac{\pi^{2}}{3} \frac{k^{2} T}{e} \frac{d \ln \sigma(E)}{d E}\right|_{E=E_{F}}=\frac{\pi^{2}}{3} \frac{k^{2} T}{e}\left[\frac{1}{n} \frac{d n(E)}{d E}+\frac{1}{\mu} \frac{d \mu(E)}{d E}\right]_{E=E_{F}},
$$

where $\sigma(E)=e n(E) \mu(E)$ is the electronic conductivity determined as a function of the band Fermi energy. Here, the Seebeck coefficient depends on the energy derivative of the energy-dependent electrical conductivity $\sigma(E)$ taken at the Fermi energy $E_{F},{ }^{57}$ as displayed in Figure $7 \mathrm{a}$ and $\mathrm{b}$, and the slope $\mathrm{dln} \sigma(E) / d E$ increases because of the increased energy-dependence of $n(E)$ resulting from the local increase in $g(E)$, leading to the enhancement of the Seebeck coefficient. ${ }^{18,58}$ Moreover, owing to the increased electrical conductivity and Seebeck coefficient, the calculated power factor values $\alpha^{2} \sigma$ range from $10.34 \times 10^{-4}$ to $14.23 \times 10^{-4} \mathrm{~W} \mathrm{~m}^{-1} \mathrm{~K}^{-2}$ at $973 \mathrm{~K}$ for all the samples are shown in Supplementary Figure S9, and the maximum power factor is $14.23 \times 10^{-4} \mathrm{~W} \mathrm{~m}^{-1} \mathrm{~K}^{-2}$ at $973 \mathrm{~K}$ in the $\mathrm{TiC}_{0.1} \mathrm{O}_{0.9} @ \mathrm{TiO}_{\mathrm{y}^{-}}$ $5 \mathrm{wt} . \% \mathrm{TiO}_{2}$ bulk. With increasing temperature, both the electric conductivity and Seebeck coefficient increase monotonously; a similar phenomenon has been observed in previous works. ${ }^{59-61}$ This phase transformation may be the second transformation because there is no obvious endothermic or exothermic effect observed in the differential scanning calorimetry measurement. Currently, the nature of this phase transformation in the $\mathrm{TiC}_{1-\mathrm{x}} \mathrm{O}_{\mathrm{x}} @ \mathrm{TiO}_{\mathrm{y}}-\mathrm{TiO}_{2}$ system remains unclear, and a detailed structural investigation and analysis is necessary.

The thermal conductivities for the $\mathrm{TiC}_{1-\mathrm{x}} \mathrm{O}_{\mathrm{x}} @ \mathrm{TiO}_{\mathrm{y}}-5 \mathrm{wt} . \% \mathrm{TiO}_{2}$ bulks are shown in Figure $6 \mathrm{c}$. The thermal conductivities of all the bulks increase slowly with temperature from 300 to $973 \mathrm{~K}$, and the thermal conductivity increases from $1.55 \mathrm{~W} \mathrm{~m}^{-1} \mathrm{~K}^{-1}$ for the $x=0.6$ sample to $1.65 \mathrm{~W} \mathrm{~m}^{-1} \mathrm{~K}^{-1}$ for the $x=0.9$ sample at $973 \mathrm{~K}$. This increase originates from the porosity of the $\mathrm{TiC}_{1-\mathrm{x}} \mathrm{O}_{\mathrm{x}} @ \mathrm{TiO}_{\mathrm{y}}-5 \mathrm{wt} . \%$ $\mathrm{TiO}_{2}$ bulks, and the bulks with more porosity exhibit lower thermal conductivity because the porosity effectively scattering the electrons and phonons can reduce the thermal conductivity. ${ }^{55}$ Furthermore, benefiting from the enhanced electrical conductivity, Seebeck coefficient and moderate thermal conductivity, the $Z T$ value in Figure $6 \mathrm{~d}$ can be improved up to 0.84 at $973 \mathrm{~K}$ for the $\mathrm{TiC}_{0.1} \mathrm{O}_{0.9} @ \mathrm{TiO}_{\mathrm{y}}-5 \mathrm{wt} . \%$ $\mathrm{TiO}_{2}$ heterostructured sample, which is the largest value observed for $\mathrm{n}$-type oxide thermoelectric materials.

\section{Thermoelectric mechanism of $\mathrm{TiC}_{1-\mathrm{x}} \mathrm{O}_{\mathrm{x}} @ \mathrm{TiO}_{\mathrm{y}}-\mathrm{TiO}_{2}$ heterostructures}

Understanding the mechanism of the enhanced Seebeck coefficient and power factor in the all-oxide $\mathrm{TiC}_{1-\mathrm{x}} \mathrm{O}_{\mathrm{x}} @ \mathrm{TiO}_{\mathrm{y}}-\mathrm{TiO}_{2}$ heterostructures is of key importance. To this end, we focused on the principle of the double-barrier filtering effect on the $\mathrm{TiC}_{1-\mathrm{x}} \mathrm{O}_{\mathrm{x}} @ \mathrm{TiO}_{\mathrm{y}}-\mathrm{TiO}_{2}$ heterostructured bulk. In these heterostructures, the Fermi level $\mathrm{E}_{F}$ of $\mathrm{TiC}_{1-\mathrm{x}} \mathrm{O}_{\mathrm{x}}$, considering the $\mathrm{TiC}_{0.5} \mathrm{O}_{0.5}$ bulk for example in Figure $7 \mathrm{c}$, is positioned inside the conductivity band; however, the Fermi level $\mathrm{E}_{F}$ of the $\mathrm{TiO}_{2}$ nanoparticle in Figure $7 \mathrm{~d}$ is located near the valence conductivity as is that of $\mathrm{TiO}_{\mathrm{y}}{ }^{62}$ Furthermore, the composite of $\mathrm{TiC}_{1-\mathrm{x}} \mathrm{O}_{\mathrm{x}}$ with a narrow band gap and high electrical conductivity, in combination with $\mathrm{TiO}_{\mathrm{y}}$ and $\mathrm{TiO}_{2}$ nanoparticles with relatively wide band gaps and effective barrier heights for energy filtering, can be used to construct the multiple heterostructures, which can be highly advantageous for thermoelectric applications because of the expected increase in the power factor. ${ }^{63-65}$ The thermoelectric mechanism of the $\mathrm{TiC}_{1-\mathrm{x}} \mathrm{O}_{\mathrm{x}} @ \mathrm{TiO}_{\mathrm{y}}-\mathrm{TiO}_{2}$ heterostructures is illustrated in Figure 8. Moreover, the all-oxide $\mathrm{TiC}_{1-\mathrm{x}} \mathrm{O}_{\mathrm{x}} @ \mathrm{TiO}_{\mathrm{y}}-\mathrm{TiO}_{2}$ heterostructures with the graded potential barrier in Figure 8a can build the double-barrier to filter the charge carrier transfer, ${ }^{43,65}$ where the first interfacial $\mathrm{TiO}_{\mathrm{y}}$ barrier at the $\mathrm{TiC}_{1-\mathrm{x}} \mathrm{O}_{\mathrm{x}} @ \mathrm{TiO}_{\mathrm{y}}$ interface selectively scatters low-energy carriers rather than high-energy carriers, and the $\mathrm{TiO}_{2}$ barrier at the 

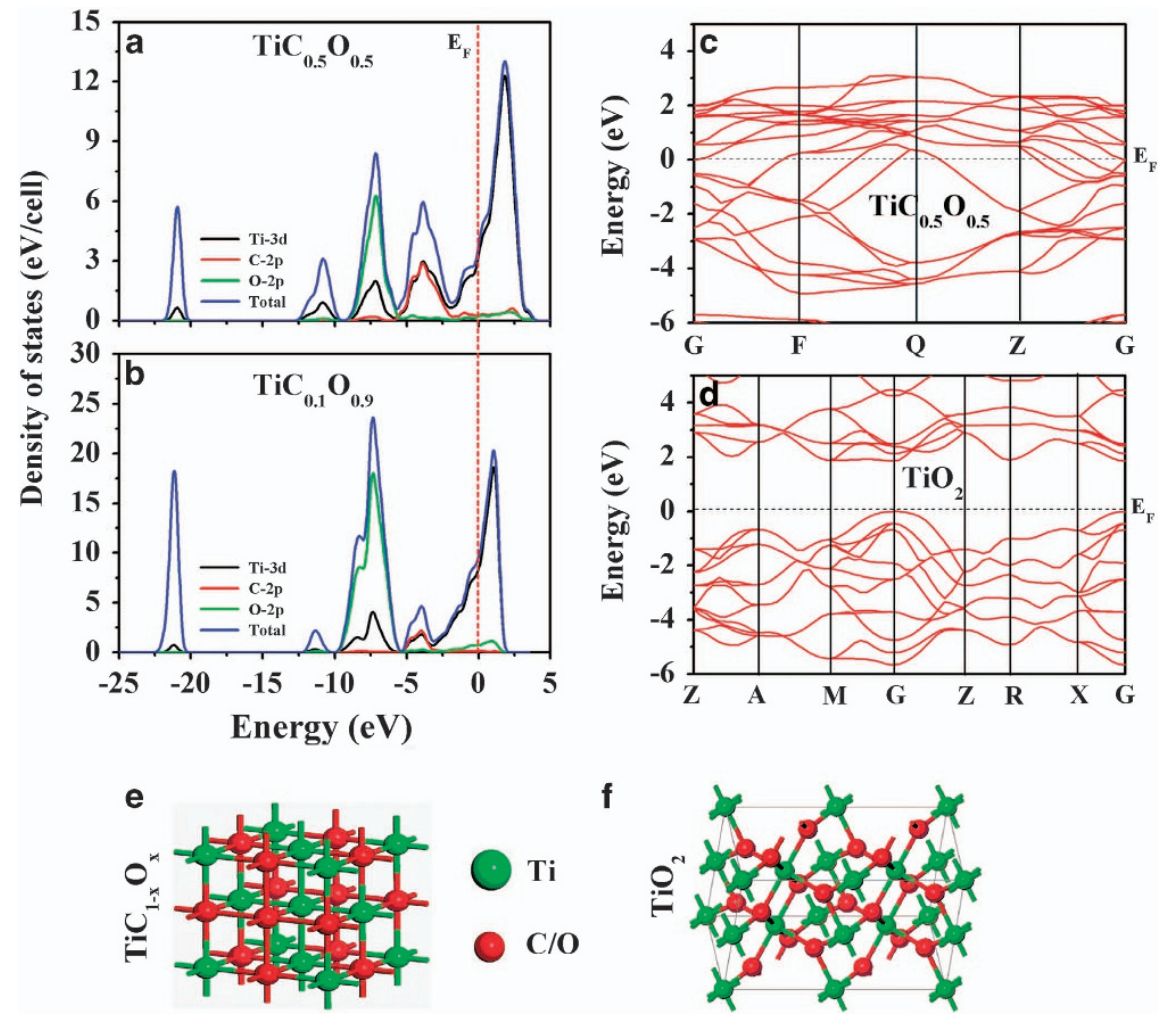

Figure 7 The total density of states (DOS) of $\mathrm{TiC}_{1-x} \mathrm{O}_{x}$ samples: (a) $\mathrm{TiC}_{0.5} \mathrm{O}_{0.5}$ and (b) $\mathrm{TiC}_{0.1} \mathrm{O}_{0.9}$; the electronic band structure of (c) $\mathrm{TiC}_{0.5} \mathrm{O}_{0.5}$ and (d) $\mathrm{TiO}_{2}$; (e) $\mathrm{TiC}_{1-x} \mathrm{O}_{x}$ and (f) $\mathrm{TiO}_{2}$ structures. The Fermi energy is at zero.

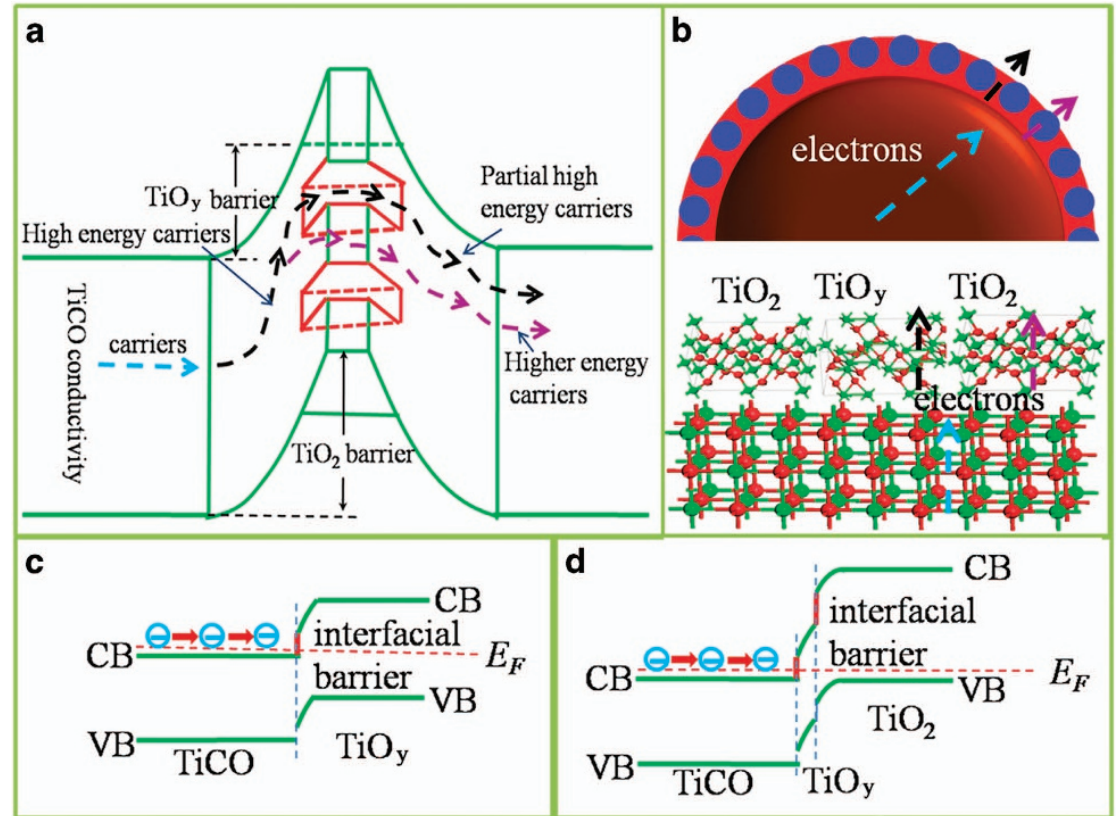

Figure 8 The mechanism of carrier transport between the double-barrier via heterostructures: (a) the path of the carriers where the first interfacial TiO barrier at the $\mathrm{TiC}_{1-\mathrm{x}} \mathrm{O}_{\mathrm{x}} @ \mathrm{TiO}_{\mathrm{y}}$ interface selectively scatters low-energy carriers rather than high-energy carriers and the $\mathrm{TiO}_{2}$ barrier at the $\mathrm{TiC}_{1-\mathrm{x}} \mathrm{O}_{\mathrm{x}} @ \mathrm{TiO} \mathrm{O}_{\mathrm{y}}-\mathrm{TiO}_{2}$ interface can further scatter partial high-energy carriers rather than higher ones; (b) transmission mechanism schemes of the carriers in the as-prepared heterostructures and carriers transporting at the heterostructured interface and in both semi-conductors, respectively; (c) and (d) present band diagrams of the all-oxide $\mathrm{TiC}_{1-x} \mathrm{O}_{\mathrm{x}} @ \mathrm{TiO}_{\mathrm{y}}-\mathrm{TiO}_{2}$ and $\mathrm{TiC}_{1-\mathrm{x}} \mathrm{O}_{\mathrm{x}} @ \mathrm{TiO}_{\mathrm{y}}-\mathrm{TiO}_{2}$ heterostructured interface, respectively.

$\mathrm{TiC}_{1-\mathrm{x}} \mathrm{O}_{\mathrm{x}} @ \mathrm{TiO}_{\mathrm{y}}-\mathrm{TiO}_{2}$ interface can further scatter partial high-energy carriers rather than higher ones. ${ }^{66-68}$ Notably, the channel between the $\mathrm{TiO}_{2}$ particles shown in Figure 8b can allow partial high-energy carriers to pass through, which can be useful for electric transport. In addition, as illustrated in Figure $8 \mathrm{c}$ and $\mathrm{d}$, the transport characteristics of charge electrons across the heterostructured interface 
are most likely determined by the height of the potential barrier between the conduction band levels of the all-oxides. Consequently, most low-energy carriers scattered by the $\mathrm{TiO}_{\mathrm{y}}-\mathrm{TiO}_{2}$ double-barrier can lead to enhancement of the Seebeck coefficient, and the higher energy carriers can conduct better than the lower energy ones such that these heterostructures can maintain a relatively high mobility and electrical conductivity. Overall, the carrier double-barrier filtering effect of the $\mathrm{TiC}_{1-\mathrm{x}} \mathrm{O}_{\mathrm{x}} @ \mathrm{TiO}_{\mathrm{y}}-\mathrm{TiO}_{2}$ heterostructures can substantially enhance the thermoelectric performance.

In conclusion, $\mathrm{TiC}_{1-\mathrm{x}} \mathrm{O}_{\mathrm{x}} @ \mathrm{TiO}_{\mathrm{y}}-\mathrm{TiO}_{2}$ composites have been successfully fabricated via facile anodization in assistance with a sol-gel chemical route to enhance their thermoelectric performance. The power factor of the $\mathrm{TiC}_{0.5} \mathrm{O}_{0.5} @ \mathrm{TiO}_{\mathrm{y}}$ heterostructure bulks prepared via 8 - $\mathrm{V}$ anodization reach up to $3.8 \times 10^{-4} \mathrm{Wm}^{-1} \mathrm{~K}^{-2}$; furthermore, the thermoelectric performance of the $\mathrm{TiC}_{0.1} \mathrm{O}_{0.9} @ \mathrm{TiO}_{\mathrm{y}}-5 \mathrm{wt} . \% \mathrm{TiO}_{2}$ heterostructured sample with $8-\mathrm{V}$ anodization can be enhanced to a high power factor over $14.23 \times 10^{-4} \mathrm{~W} \mathrm{~m}^{-1} \mathrm{~K}^{-2}$ and a high dimensionless figure of merit up to 0.84 at $973 \mathrm{~K}$, demonstrating that the heterostructures can increase the Seebeck coefficient while maintaining a relatively high electrical conductivity in addition to reducing phonon thermal conductivity via a possible carrier double-barrier filtering effect at the $\mathrm{TiC}_{1-\mathrm{x}} \mathrm{O}_{\mathrm{x}} @ \mathrm{TiO}_{\mathrm{y}}-\mathrm{TiO}_{2}$ heterostructured interface, where low-energy carriers can be scattered more strongly than highenergy carriers by the appropriately engineered interfacial barrier. Thus, the strategy of improving the power factor via rational heterostructure engineering of the multiple semiconductor interfaces of all-oxide composites may stand out as a promising route to achieve high-performance thermoelectric materials.

\section{CONFLICT OF INTEREST}

The authors declare no conflict of interest.

\section{ACKNOWLEDGEMENTS}

We gratefully acknowledge the financial support provided by the National Science Foundation of China (no. 51472027), Beijing High School Youth Talent Plan (YETP0351), National Basic Research Program of China (973 Program, no. 2013CB632404) and National High Technology Research and Development Program of China (863 Program, no. 2012AA062302).

1 Venkatasubramanian, V. R., Siivola, E., Colpitts, T. \& O'Quinn, B. Thin-film thermoelectric devices with high room-temperature figures of merit. Nature 413 , 597-602 (2001)

2 Bell, L. E. Cooling, heating, generating power, and recovering waste heat with thermoelectric systems. Science 321, 1457-1461 (2008).

3 Tritt, T. M. Holey and unholey semiconductors. Science 283, 804-805 (1999).

4 Tritt, T. M. \& Subramanian, M. A. Thermoelectric materials, phenomena, and applications: A bird's eye view. MRS Bull 31, 188-229 (2006).

5 Li, J. F., Liu, W. S., Zhao, L. D. \& Zhou, M. High-performance nanostructured thermoelectric materials. NPG Asia Mater 2, 152-158 (2010).

6 Majumdar, A. Thermoelectricity in semiconductor nanostructures. Science 303, 777-778 (2004)

7 Zhang, L. J. \& Singh, D. J. Electronic structure and thermoelectric properties of layered PbSe-WSe 2 materials. Phys. Rev. B 80, 075117 (2009).

8 Scheele, M., Oeschler, N., Meier, K., Kornowski, A., Klinke, C. \& Weller, H. Synthesis and Thermoelectric characterization of $\mathrm{Bi}_{2} \mathrm{Te}_{3}$ nanoparticles. Adv. Funct. Mater. 19, 3476-3483 (2009).

9 Koga, T., Sun, X., Cronin, S. B. \& Dresselhaus, M. S. Carrier pocket engineering applied to "strained" Si/Ge superlattices to design useful thermoelectric materials. Appl. Phys. Lett. 75, 2438 (1999).

10 Nakahara, J. F., Takeshita, T., Tschetter, M. J., Beaudry, B. J. \& Gschneidner, K. A. Thermoelectric properties of lanthanum sulfide with $\mathrm{Sm}, \mathrm{Eu}$, and $\mathrm{Yb}$ additives. J. Appl. Phys. 63, 2331 (1988).

11 Nishida, I. Study of semiconductor-to-metal transition in Mn-doped FeSi 2 . Phys. Rev. B 7, 2710 (1973).
12 Mehta, R. J., Zhang, Y. L., Karthik, C., Singh, B., Siegel, R. W., Borca-Tasciuc, T. \& Ramanath, G. A new class of doped nanobulk high-figure-of-merit thermoelectrics by scalable bottom-up assembly. Nat. Mater. 11, 233-240 (2012).

13 Biswas, K., He, J., Blum, I. D., Wu, C. I., Hogan, T. P., Seidman, D. N., Dravid, V. P. \& Kanatzidis, M. G. High-performance bulk thermoelectrics with all-scale hierarchical architectures. Nature 489, 414-418 (2012).

14 Zhou, M., Li, J. F. \& Kita, T. Nanostructured $\mathrm{AgPb}_{m} \mathrm{SbTe}_{\mathrm{m}+2}$ system bulk materials with enhanced thermoelectric performance. J. Am. Chem. Soc. 130, 4527-4532 (2008).

15 Joshi, G., Lee, H., Lan, Y. C., Wang, X. W., Zhu, G. H., Wang, D. Z., Gould, R. W., Cuff, D. C., Tang, M. Y., Dresselhaus, M. S., Chen, G. \& Ren, Z. F. Enhanced thermoelectric figure-of-merit in nanostructured p-type silicon germanium bulk alloys. Nano Lett. 8, 4670-4674 (2008).

16 Pei, Y. Z., Heinz, N. A., LaLonde, A. \& Snyder, G. J. Combination of large nanostructures and complex band structure for high performance thermoelectric lead telluride. Energy Environ. Sci 4, 3640-3645 (2011).

17 Rhyee, J. S., Lee, K. H., Lee, S. M., Cho, E., Kim, S. I., Lee, E., Kwon, Y. S., Shim, J. H. \& Kotliar, G. Peierls distortion as a route to high thermoelectric performance in $\mathrm{In}_{4} \mathrm{Se}_{3-\delta}$ crystals. Nature 459, 965-968 (2009).

18 Heremans, J. P., Jovovic, V., Toberer, E. S., Saramat, A., Kurosaki, K., Charoenphakdee, A., Yamanaka, S. \& Snyder, G. J. Enhancement of thermoelectric efficiency in $\mathrm{PbTe}$ by distortion of the electronic density of states. Science 321, 554-557 (2008).

19 Okuda, T., Nakanishi, K., Miyasaka, S. \& Tokura, Y. Large thermoelectric response of metallic perovskites: $\mathrm{Sr}_{1-x} \mathrm{La}_{x} \mathrm{TiO}_{3}(0<\sim \mathrm{x}<\sim 0.1)$. Phys. Rev. B. 63, 113104 (2001).

20 Zhao, L. D., He, J. Q., Berardan, D., Lin, Y. H., Li, J. F., Nan, C. W. \& Dragoe, N. BiCuSeO oxyselenides: new promising thermoelectric materials. Energy Environ. Sci. 7, 2900-2924 (2014).

21 Liu, Y., Zhao, L. D., Liu, Y. C., Lan, J., Xu, W., Li, F., Zhang, B. P., Berardan, D., Dragoe, N., Lin, Y. H., Nan, C. W., Li, J. F. \& Zhu, H. M. Remarkable enhancement in thermoelectric performance of BiCuSeO by Cu deficiencies. J. Am. Chem. Soc. 133 20112-20115 (2011).

22 Li, F., Li, J. F., Zhao, L. D., Xiang, K., Liu, Y., Zhang, B. P., Lin, Y. H., Nan, C. W. \& Zhu, H. M. Polycrystalline BiCuSeO oxide as a potential thermoelectric material. Energy Environ. Sci 5, 7188-7195 (2012).

23 Pei, Y. L.i., He, J. Q., Li, J. F., Li, F., Liu, Q. J., Pan, W., Barreteau, C., Berardan, D., Dragoe, N. \& Zhao, L. D. High thermoelectric performance of oxyselenides: intrinsically low thermal conductivity of Ca-doped BiCuSeO. NPG Asia Mater 5, 1-9 (2013).

24 Sui, J. H., Li, J., He, J. Q., Pei, Y. L., Berardan, D., Wu, H. J., Dragoe, N., Cai, W. \& Zhao, L. D. Texturation boosts the thermoelectric performance of BiCuSeO oxyselenides. Energy Environ. Sci. 6, 2916-2920 (2013).

25 Liu, C. Y., Miao, L., Zhou, J. H., Huang, R. \& Tanemura, S. Bottom-up assembly to $\mathrm{Ag}$ nanoparticles embedded $\mathrm{Nb}$-doped $\mathrm{TiO}_{2}$ nanobulks with improved n-type thermoelectric properties. J. Mater. Chem. 22, 14180-14190 (2012).

$26 \mathrm{He}$, Q. Y., Hao, Q., Chen, G., Poudel, B., Wang, X. W., Wang, D. Z. \& Ren, Z. F. Thermoelectric property studies on bulk $\mathrm{TiO}_{\mathrm{x}}$ with $\mathrm{x}$ from 1 to 2. Appl. Phys. Lett. 91, 052505 (2007).

27 Okinaka, N. \& Akiyama, T. Latent property of defect-controlled metal oxide: nonstoichiometric titanium oxides as prospective material for high-temperature thermoelectric conversion. Jpn. J. Appl. Phys. Part 1 45, 7009 (2006).

28 Mikami, M. \& Ozaki, K. Thermoelectric properties of nitrogen-doped $\mathrm{TiO}_{2}-\mathrm{x}$ compounds. J. Phy. Conf. Series 379, 012006 (2012).

29 Bak, T., Nowotny, J., Rekas, M. \& Sorrell, C. C. Thermoelectric power of mixed electronic-ionic conductors II. Case of titanium dioxide. Ionics 10, 166-176 (2004).

30 Jiao, S. Q. \& Zhu, H. M. Electrolysis of $\mathrm{Ti}_{2} \mathrm{CO}$ solid solution prepared by $\mathrm{TiC}$ and $\mathrm{TiO}_{2}$. J. Alloys Compd 438, 243-246 (2007)

$31 \mathrm{Liu}$, Y., Ou, C. L., Hou, J. G. \& Zhu, H. M. Effect of coated $\mathrm{TiO}_{2}$ nano-particle on thermoelectric performance of $\mathrm{TiC}_{0.5} \mathrm{O}_{0.5}$ ceramics. J. Alloys Compd 531, 5-9 (2012).

32 Enyashin, A. N. \& Ivanovskii, A. L. Structural, cohesive and electronic properties of titanium oxycarbides $\left(\mathrm{TiC}_{x} \mathrm{O}_{1-x}\right)$ nanowires and nanotubes: DFT modelling. Chem. Phys. 362, 58-64 (2009).

33 He, M., Ge, J., Lin, Z. Q., Feng, X. H., Wang, X. W., Lu, H. B., Yang, Y. L. \& Qiu, F. Thermopower enhancement in conducting polymer nanocomposites via carrier energy scattering at the organic-inorganic semiconductor interface. Energy Environ. Sci 5, 8351-8358 (2012).

34 Bahk, J. H., Santhanam, P., Bian, Z. X., Ram, R. \& Shakouri, A. Resonant carrier scattering by core-shell nanoparticles for thermoelectric power factor enhancement. Appl. Phys. Lett. 100, 012102 (2012).

35 Qu, X. R., Wang, W., Liu, W., Yang, Z. H., Duan, X. M. \& Jia, D. C. Antioxidation and thermoelectric properties of $\mathrm{ZnO}$ nanoparticles-coated $\beta-\mathrm{FeSi}_{2}$. Mater. Chem. Phys. 129, 331-336 (2011)

36 Zide, M. O., Vashaee, D., Bian, Z. X., Zeng, G., Bowers, J. E., Shakouri, A. \& Gossard, A. C. Demonstration of electron filtering to increase the Seebeck coefficient in $\mathrm{In}_{0.53} \mathrm{Ga}_{0.47} \mathrm{As} / \mathrm{In}_{0.53} \mathrm{Ga}_{0.28} \mathrm{Al}_{0.19}$ As superlattices. Phys. Rev. B 74, 205335 (2006).

37 Zide, M. O., Bahk, J. H., Singh, R., Zebarjadi, M., Zeng, G., Lu, H., Feser, J. P., Xu, D., Singer, S. L., Bian, Z. X., Majumdar, A., Bowers, J. E., Shakouri, A. \& Gossard, A. C. High efficiency semimetal/semiconductor nanocomposite thermoelectric materials. J. Appl. Phys. 108, 123702 (2010).

38 Bahk, J. H., Bian, Z. X., Zebarjadi, M., Zide, M. O., Lu, H., Xu, D. Y., Feser, J. P., Zeng, G., Majumdar, A., Gossard, A. C., Shakouri, A. \& Bowers, J. E. Thermoelectric figure of merit of $\left(\operatorname{In}_{0.53} \mathrm{Ga}_{0.47} A s\right)_{0.8}\left(\operatorname{In}_{0.52} \mathrm{Al}_{0.48} A s\right)_{0.2}$ III-V semiconductor alloys. Phys. Rev. B 81, 235209 (2010).

$39 \mathrm{Li}$, J. H., Tan, Q., Li, J. F., Liu, D. W., Li, F., Li, Z. Y., Zou, M. M. \& Wang, K. BiSbTe-based nanocomposites with high ZT: the effect of $\mathrm{SiC}$ nanodispersion on thermoelectric properties. Adv. Funct. Mater. 23, 4317-4323 (2013). 
40 Zhang, G. Q., Wang, W. \& Li, X. G. Enhanced thermoelectric properties of core/shell heterostructure nanowire composites. Adv. Mater. 20, 3654-3656 (2008).

41 Bahk, J. H., Bian, Z. X., Zebarjadi, M., Santhanam, P., Ram, R. \& Shakouri, A. Effect of $\mathrm{Sn}$ substitution on the thermoelectric properties of nanostructured bulk $\mathrm{Bi}_{2-x} \mathrm{Sb}_{x} \mathrm{Te}_{3}$ alloy. Mater. Res. Soc. Symp. Proc. 1329 (2011).

42 Houlihan, J. F., Danley, W. J. \& Mulay, L. N. Magnetic susceptibility and EPR spectra of titanium oxides: Correlation of magnetic parameters with transport properties and composition. J. Solid State Chem. 12, 265-269 (1975).

43 Zebarjadi, M., Shakouri, A. \& Esfarjani, K. Thermoelectric transport perpendicular to thin-film heterostructures calculated using the Monte Carlo technique. Phys. Rev. B 74, 195331 (2006)

44 Zhang, Y. C., Snedaker, M. L., Birkel, C. S., Ji, X. L., Shi, Y. F., Liu, D., Liu, X. N., Moskovits, M. M. \& Stucky, G. D. Silver-based intermetallic heterostructures in $\mathrm{Sb}_{2} \mathrm{Te}_{3}$ thick films with enhanced thermoelectric power factors. Nano Lett. 12, 1075-1080 (2012).

45 Ohta, H., Kim, S., Mune, Y., Mizoguchi, T., Nomura, K., Ohta, S., Nomura, T., Nakanishi, Y., Ikuhara, Y., Hirano, M., Hosono, H. \& Koumoto, K. Giant thermoelectric Seebeck coefficient of a two-dimensional electron gas in $\mathrm{SrTiO}_{3}$. Nat. Mater. 6, 129-134 (2007).

46 Mun, J., Kim, S. W., Kato, R., Hatta, I., Lee, S. H. \& Kang, K. H. Measurement of the thermal conductivity of $\mathrm{TiO}_{2}$ thin films by using the thermo-reflectance method. Thermochimica Acta 455, 55-59 (2007).

47 Hicks, L. D. \& Dresselhaus, M. S. Effect of quantum-well structures on the thermoelectric figure of merit. Phys. Rev. B 47, 12727 (1993).

48 Zhao, L. D., Zhang, B. P., Liu, W. S., Zhang, H. L. \& Li, J. F. Enhanced thermoelectric properties of bismuth sulfide polycrystals prepared by mechanical alloying and spark plasma sintering. J. Solid State Chem. 181, 3278-3282 (2008).

49 Chiritescu, C., Cahill, D. G., Nguyen, N., Johnson, D., Bodapati, A., Keblinski, P. \& Zschack, P. Ultralow thermal conductivity in disordered, layered WSe $\mathrm{W}_{2}$ crystals. Science 315, 351-353 (2007).

50 Kim, W., Zide, J., Gossard, A., Klenov, D., Stemmer, S., Shakouri, A. \& Majumdar, A. Thermal conductivity reduction and thermoelectric figure of merit increase by embedding nanoparticles in crystalline semiconductor. Phys. Rev. Lett. 96, 045901 (2006)

51 Venkatasubramanian, R. Lattice thermal conductivity reduction and phonon localizationlike behavior in superlattice structures. Phys. Rev. B 61, 3091 (2006).

52 Jeng, M. S., Yang, R. G., Song, D. \& Chen, G. Modeling the thermal conductivity and phonon transport in nanoparticle composites using monte carlo simulation. J. Heat Transfer. 130, 042410 (2008).

53 Huxtable, S. T., Abramson, A. R., Tien, C. L., Majumdar, A., LaBounty, C., Fan, X. F., Zeng, G., Bowers, J. E., Shakouri, A. \& Croke, E. T. Thermal conductivity of Si/SiGe and SiGe/SiGe superlattices. Appl. Phys. Lett. 10, 1737 (2002).

54 Jiang, B., Hou, N., Huang, S. Y., Zhou, G. G., Hou, J. G., Cao, Z. M. \& Zhu, H. M. Structural studies of $\mathrm{TiC}_{1-x} \mathrm{O}_{x}$ solid solution by Rietveld refinement and first-principles calculations. J. Solid State Chem. 204, 1-8 (2013).

55 Liu, Y., Lin, Y. H., Xu, W., Cheng, B., Lan, J. L., Chen, D. L., Zhu, H. M. \& Nan, C. W. High-temperature transport property of $\ln _{2-x} \mathrm{Ce}_{\mathrm{x}} \mathrm{O}_{3} \quad(0 \leq \mathrm{x} \leq 0.10)$ fine grained ceramics. J. Am. Ceram. Soc. 95, 2568-2572 (2012).
56 Cutler, M. \& Mott, N. F. Observation of anderson localization in an electron gas. Phys. $\operatorname{Rev} 181,1336$ (1969).

57 Sootsman, J. R., Chung, D. Y. \& Kanatzidis, M. G. New and old concepts in thermoelectric materials. Angew. Chem. Int. Ed. 48, 8616-8639 (2009).

$58 \mathrm{Hao}, \mathrm{L}$. \& Lee, T. K. Thermopower of gapped bilayer grapheme. Phys. Rev. B 81 165445 (2010).

59 Okinaka, N. \& Akiyama, T. Thermoelectric properties of non-stoichiometric titanium oxides for waste heat recovery in steelworks. ISIJ Int. 50, 1296-1299 (2010).

60 Liu, F. S., Zheng, J. X., Huang, M. J., He, L. P., Ao, W. Q., Pan, F. \& Li, J. Q. Enhanced thermoelectric performance of $\mathrm{Cu}_{2} \mathrm{CdSnSe}_{4}$ by $\mathrm{Mn}$ doping: experimental and first principles studies, Sci. Rep 4, 5774 (2014).

61 Zeier, W. G., LaLonde, A., Gibbs, Z. M., Heinrich, C. P., Panthöfer, M., Snyder, G. J. \& Tremel, W. Influence of a nano phase segregation on the thermoelectric properties of the p-type doped stannite compound $\mathrm{Cu}_{2+x} \mathrm{Zn}_{1-x} \mathrm{GeSe}_{4}$. J. Amer. Chem. Soc. 134 7147-7154 (2012).

62 Andersson, D. A., Korzhavyi, P. A. \& Johansson, B. Thermodynamics of structural vacancies in titanium monoxide from first-principles calculations. Phys. Rev. B 71, 144101 (2005)

63 Vineis, C. J., Shakouri, A., Majumdar, A. \& Kanatzidis, M. G. Nanostructured thermo electrics: big efficiency gains from small features. Adv. Mater. 22, 3970-3980 (2010).

64 Kanatzidis, M. G. Nanostructured thermoelectrics: The new paradigm? Chem. Mater 22 648-659 (2010).

65 Liu, Y. F., Sahoo, P., Makongo, J., Zhou, X. Y., Kim, S. J., Chi, H., Uher, C., Pan, X. Q. \& Poudeu, P. Large enhancements of thermopower and carrier mobility in quantum dot engineered bulk semiconductors. J. Am. Chem. Soc. 135, 7486-7495 (2013)

66 Zebarjadi, M., Esfarjani, K., Dresselhaus, M. S., Ren, Z. F. \& Chen, G. Perspectives on thermoelectrics: from fundamentals to device applications. Energy Environ. Sci 5, 5147-5162 (2012)

67 Scheele, M., Oeschler, N., Veremchuk, I., Peters, S. O., Littig, A., Kornowski, A. Klinke, C. \& Weller, H. Thermoelectric properties of lead chalcogenide core-shell nanostructures. ACS Nano 5, 8541-8555 (2011).

68 Sumithra, S., Takas, N. J., Misra, D. K., Nolting, W. M., Poudeu, P. \& Stokes, K. L. Enhancement in thermoelectric figure of merit in nanostructured $\mathrm{Bi}_{2} \mathrm{Te}_{3}$ with semimetal nanoinclusions. Adv. Energy Mater 1, 1141-1147 (2011).

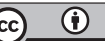

This work is licensed under a Creative Commons Attribution 4.0 International License. The images or other third party material in this article are included in the article's Creative Commons license, unless indicated otherwise in the credit line; if the material is not included under the Creative Commons license, users will need to obtain permission from the license holder to reproduce the material. To view a copy of this license, visit http:// creativecommons.org/licenses/by/4.0/

Supplementary Information accompanies the paper on the NPG Asia Materials website (http://www.nature.com/am) 